\title{
ROBLEDO DREWS Y CASTRO ARQUITECTOS (1954-1960) CRITERIOS FORMALES Y VALORES VISUALES EN EL REFUGIO Y TEATRO INFANTIL DEL CLUB LOS LAGARTOS (1955)*
}

Mario Andrés Narváez Salas**

Jorge Alberto Villamizar Hernández****

Medes da Rochar. Paulo (1987-1994). Tienda Forma. Fuente: Piñón Helio. (2005) p. 103
El presente artículo es resultado de proyecto de investigación titulado: "ARQUITECTURA MODERNA EN COLOMBIA. La obra de RDC arquitectos como material de proyecto. 1954 - 1960". Proyecto financiado por la Universidad Santo Tomás seccional Bucaramanga cuyo grupo de investigación se conformó por el Investigador: Arq. Mario Andrés Narváez Salas, el Coinvestigador: Jorge Alberto Villamizar Hernández, y e Auxiliar de investigación: Esteban Ariza. Fecha de inicio: Febrero 2009, Fecha de terminación: Mayo 2010.
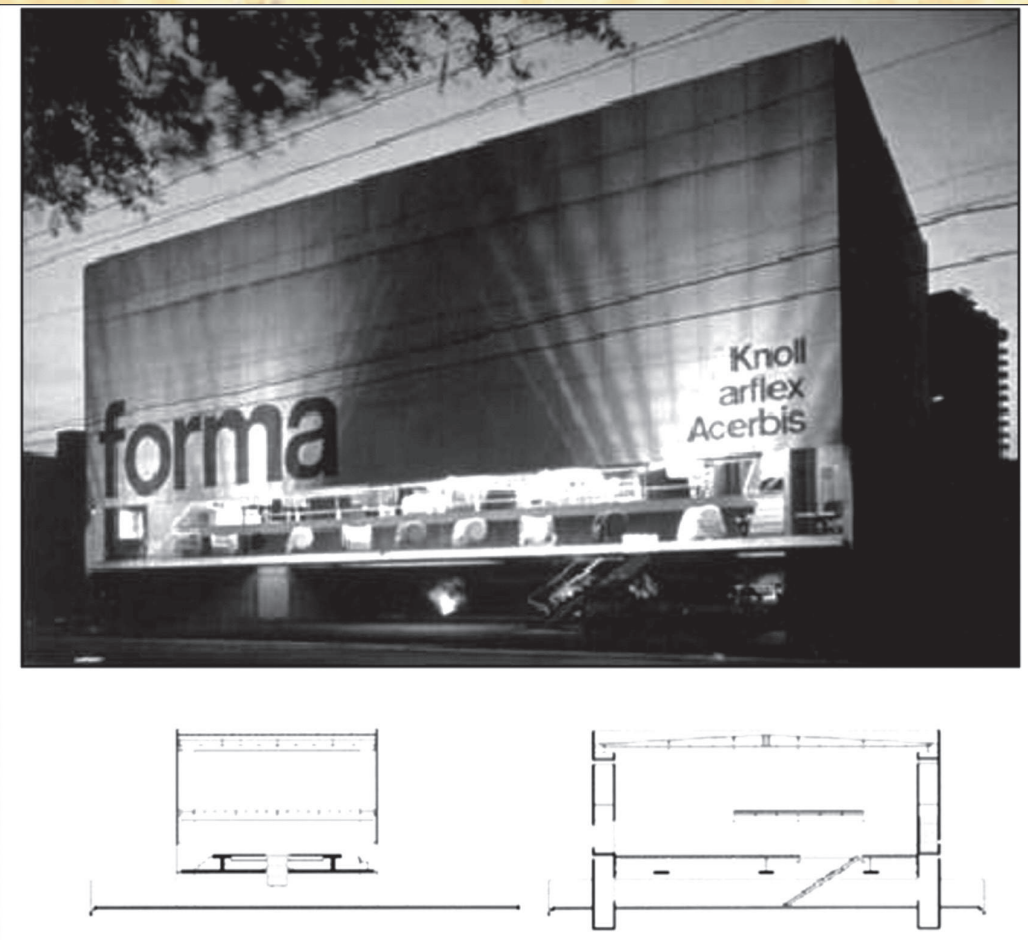

\section{RESUMEN}

Este artículo aborda la temática del reconocimiento de la arquitectura moderna en Colombia como patrimonio y su vigencia como referente proyectual. Para tal fin se presenta el reconocimiento de unos criterios formales y unos valores visuales validados como Material de Proyecto, es decir, como materia prima para proyectos arquitectónicos actuales, a partir del análisis del Refugio y teatro infantil del Club los Lagartos. Lo anterior contribuyó, por un lado, con la catalogación de la obra de Robledo, Drews y Castro Arquitectos' y, por otro lado, con la consolidación de la memoria arquitectónica del movimiento moderno en Colombia.

\section{PALABRAS CLAVE}

Criterios formales, Herramienta proyectual, Arquitectura Moderna en Colombia, Proyecto arquitectónico, Valores visuales.

\footnotetext{
Firma que se conformó en 1954 y disolvió en 1960 y que a pesar de su breve existencia generó obras de auténtica calidad arquitectónica en donde se refleja claramente el propósito de establecer orden y claridad en los planteamientos que definen y estructuran el ejercicio y propuesta arquitectónicos.
} 


\section{ROBLEDO DREWS ARCHITECTS AND CASTRO (1954-1960) FORMAL CRITERIA AND VISUAL VALUES IN THE REFUGE AND CHILDREN'S THEATRE CLUB LOS LARGATOS (1955)*}

Mario Andrés Narváez Salas***

Jorge Alberto Villamizar Hernández*****

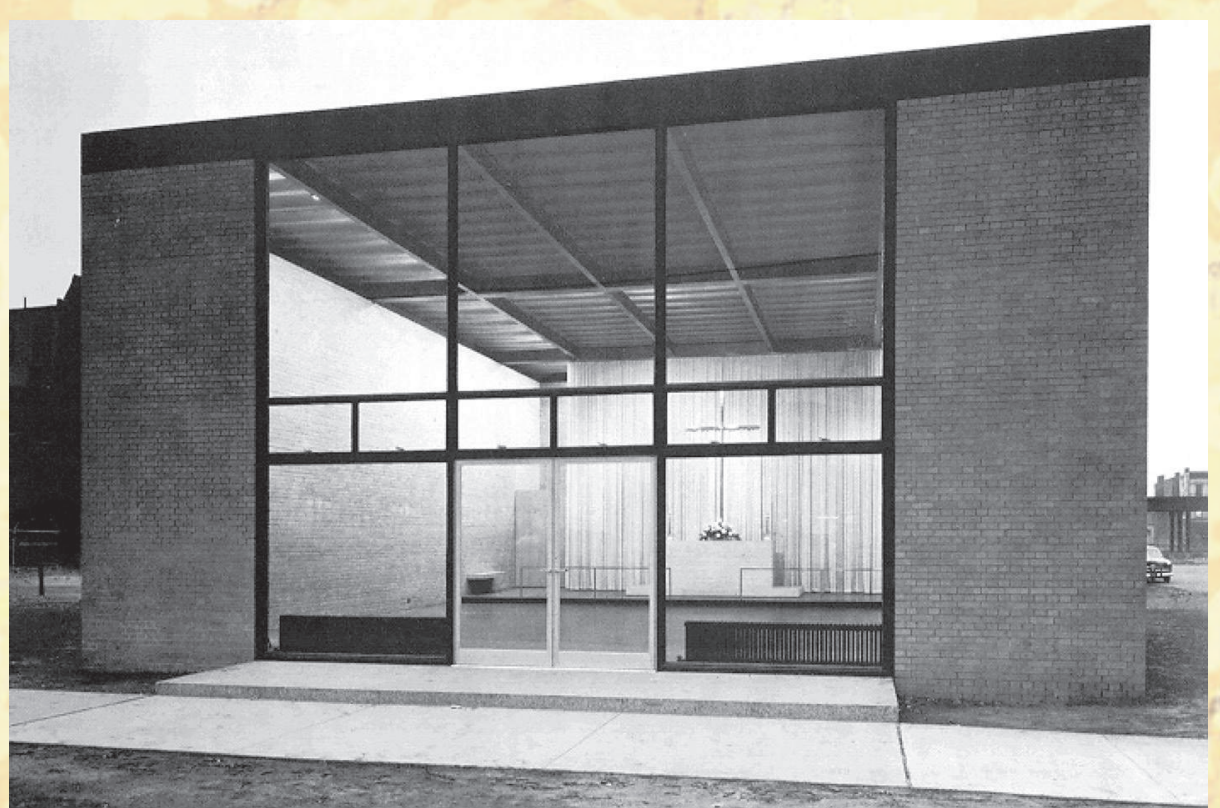

** Arquitecto. Docente Facultad de Arquitectura Universidad Santo Tomás Bucaramanga, Arquitecto Universidad Javeriana, Máster en "Teoría y práctica del Proyecto Arquitectónico" Universidad Politécnica de Cataluña, Doctorando en Proyectos Arquitectónicos Universidad Politécnica de Cataluña, mansarq@hotmail.com

*** Arquitecto. Docente Facultad de Arquitectura Universidad Santo Tomás Bucaramanga, Especialista en Proyectos arquitectónicos y en Docencia Universitaria de la misma universidad, javillamizarh@yahoo.com
Vander Rohe, Mies (1949). ITT, Chicago: Kapelle St. Savior. fuente: http://www.nhr-unibochumdelkgi/projekte/rub-expo/ks/tbu3as.gif

\section{ABSTRACT}

This article addresses the issue of recognition of modern architecture in Colombia as patrimony and its validity as a benchmark of design. To that end presents the recognition of formal criteria and visual values validated as project material, that is as raw material for current architectural projects, from analysis of the Theater and Refuge for children for the "Club Los Lagartos". This contributed, in one side with the documentation of the work of the architectural firm Robledo, Drews and Castro, by other side contributed with the consolidation of the architectural memory of the Modern Movement in Colombia.

\section{KEY WORDS}

Formal criteria, design tool, modern architecture in Colombia, visual values, architectural project, visual values. 


\section{Planteamiento del problema}

El reconocimiento actual de la arquitectura moderna como patrimonio y su vigencia como referente proyectual se ha logrado al ver la claridad y coherencia que plantea el movimiento, no en los rasgos figurativos y estilísticos más evidentes sino en unos principios estéticos esenciales que se sustentan en la construcción formal de universos ordenados a partir del entendimiento del contexto, la abstracción como la comprensión de lo esencial en las configuraciones de los elementos constitutivos del objeto y una forma consistente como una unidad equilibrada. (Ver Figura I.)

Figura I. Paulo Mendes da Rocha. (19871995). Museo Brasileño de esculturo. Fuente: Piñón, Helio. (2003). p. 10

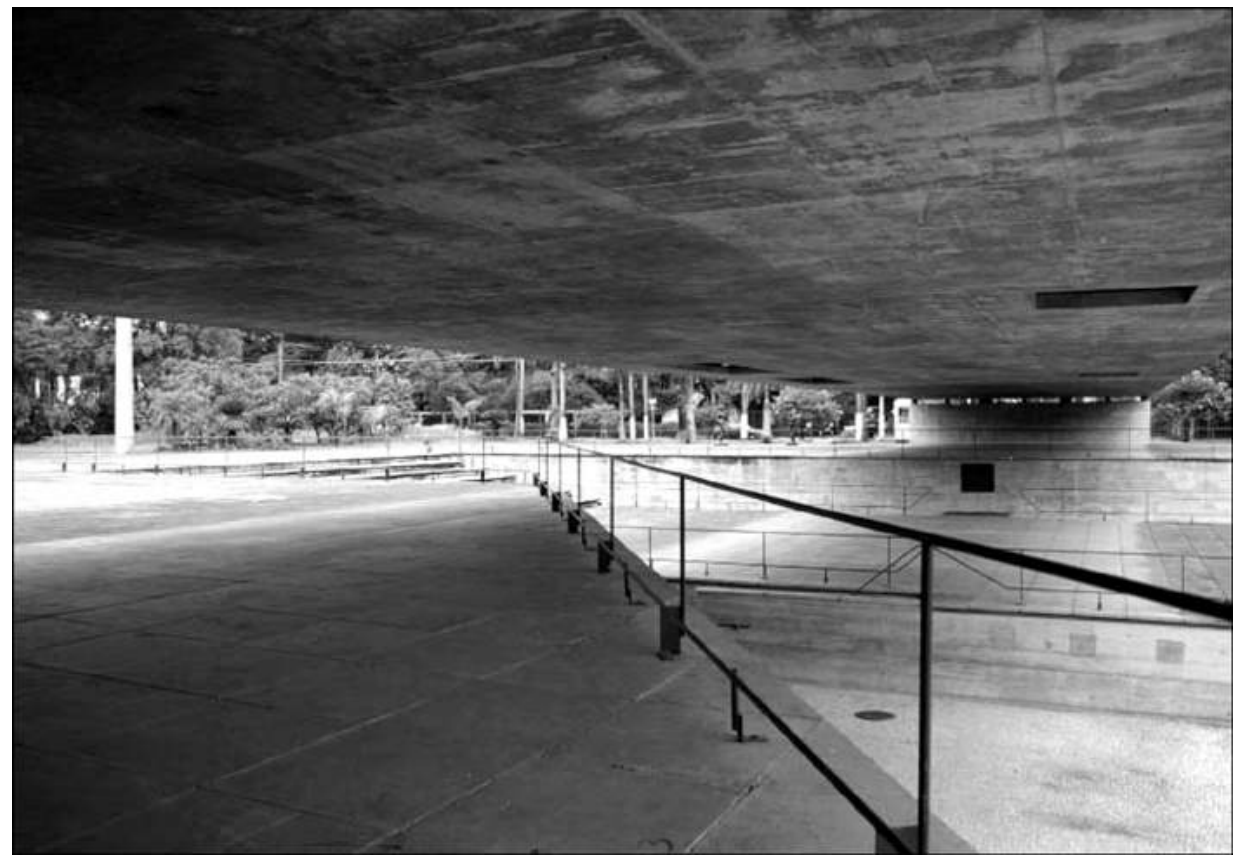

En este reconocimiento se destacan dos iniciativas a nivel internacional, por un lado el proyecto de documentación y conservación del Movimiento Moderno (DoCoMoMo Internacional), organización creada en 1990 con sede en Barcelona cuyo principal objetivo es divulgar y proteger el patrimonio arquitectónico del Movimiento Moderno ${ }^{2} y$, por otro lado, están las iniciativas del grupo FORM de la Escuela Técnica Superior de Arquitectura de Barcelona de la Universidad Politécnica de Cataluña dentro del programa de doctorado en Proyectos Arquitectónicos (2009) cuya línea de investigación en la forma moderna se enfoca en el análisis formal como un sistema de relaciones visuales que plantean unos valores reconocibles a partir del juicio estético.

En el contexto colombiano actual, la investigación y reconocimiento en el campo de la Arquitectura Moderna se observa insuficiente. Los esfuerzos que se han encaminado a difundirla como patrimonio o como referente teórico han sido revisiones generales, que si bien brindan un panorama amplio, no logran profundizar en el proyecto arquitectónico en particular, cuestión que ayudaría a esclarecer la memoria y ampliar el criterio a la hora de asumir la realidad presente habida cuenta de la historia y sus lecciones al momento de proyectar.

2 La iniciativa de DoCoMoMo llegó a Colombia en el año 2007, para consolidar una red global con sedes en Alemania, Argentina, Australia, Austria, Chile, España, Estados Unidos, Holanda, Irlanda, Japón, Corea, México, Noruega, Portugal, Suecia y Suiza. 
Por tanto, es evidente la necesidad de consolidar la memoria arquitectónica moderna en Colombia específicamente desde el entendimiento del proyecto arquitectónico, en este caso particular, la investigación plantea el reconocimiento de unos materiales de proyecto dentro de la historia, es decir, de unos "elementos, criterios o soluciones" (Piñón, 2005. p.5) validados tanto por historia como por la experiencia que se puedan constituir en materia prima a la hora de desarrollar proyectos arquitectónicos en la actualidad.

De aquí surgió el objetivo del proyecto que buscó: Reconocer los criterios formales y valores visuales validados como material de proyecto en El Refugio y Teatro Infantil del Club Los Lagartos de 1955 y la Casa Londoño de 1957, de Robledo Drews \& Castro arquitectos.

El presente artículo se centra en el análisis de uno de estos proyectos: El Refugio y Teatro Infantil del club los Lagartos de 1955.

\section{Estado del arte}

\section{Sobre El Refugio y Teatro Infantil}

Las publicaciones al respecto, se resumen en artículos publicados en la revista PROA en los números 97 (Martínez Carlos, 1956, p.3-5), 100 (Martínez Carlos, 1956. p.5) y 384 (Martínez Carlos, 1989) y una aparición en la publicación Colombia: Arquitectura Moderna de Fontana y Mallorga (2004. pp. 157-167), material que también está disponible en el Museo Virtuale di Architettura MUVA.

\section{Sobre materiales de proyecto}

El concepto se desarrolla por Piñón en la línea de investigación de la Forma Moderna de la Universidad Politécnica de Cataluña y aparece principalmente en los textos de: Materiales de Proyecto (2005. p.5), Curso básico de proyectos (1998. p. 106) y Teoría del proyecto (2006. p. I28-136).

\section{Marco teórico}

Dentro de los conceptos considerados el de material de proyecto se constituye como el elemento teórico más relevante, aquí un texto de Piñón (2006, pp. I30-132) para profundizar más en la idea:

La convicción de que la creación no reside tanto en la invención de nuevas melodías, cuanto el establecimiento de nuevos sistemas que las reelaboren y desarrollen, hizo que desde antiguo los músicos se sirviesen de materiales de la música como materia prima de sus composiciones: difícilmente Bach habría podido cumplir con su compromiso de preparar una cantata semanal mientras fue cantor de la iglesia de Santo Tomás de Leipzig, si no hubiera tomado materiales de Händel, de Vivaldi o de sí mismo, como base para sus composiciones religiosas. Y si hubiera renunciado a esos préstamos, al centrar todo el esfuerzo en la innovación de los temas, habría provocado, sin duda, una merma en la calidad de su música: asumir su cometido como una práctica circense de mera habilidad le habría desviado del proyecto musical con el que abordó el primer tercio del siglo XVIII. Mi punto de vista se aproxima al de los músicos, de modo que, a la consideración física del material, añadiría la asunción de la arquitectura propia y la de los demás -de algunos de sus criterios y soluciones- como materia prima de una actividad formadora que, en definitiva, es, a mi 
Figura 2. Van der Rohe, Mies. (1945-46). Alummni Memorial Hall. Fuente: http://www. ruhr-uni-bochum.de/kgi/projekte/rub_expo/k5/ juicio, la específica del proyecto. La imposibilidad de separar lo material de lo estético -en arquitectura y en cualquier manifestación artística- me inclina a considerar la obra como un ente complejo, compuesto de materia y proyecto, a la vez, que se nutre de materiales tanto físicos como nocionales. Todo lo anterior, en el marco de una idea de concepción que considera que su cometido se centra más en la construcción de estructuras -esto es, en la propuesta de relaciones- que en la invención de elementos primarios.

El retomar el concepto de material de proyecto en arquitectura permitirá no sólo hacer arquitectura de calidad, sino que dejará abierta la posibilidad de generar un desarrollo continuo sobre las bases de la actualización permanente y consolidar así una verdadera plataforma de desarrollo para la arquitectura en Colombia.

\section{Material de proyecto, parámetros de validación}

Uno de los resultados de la investigación fue establecer los parámetros que definen el concepto de material de proyecto para llegar a establecer las siguientes conclusiones:

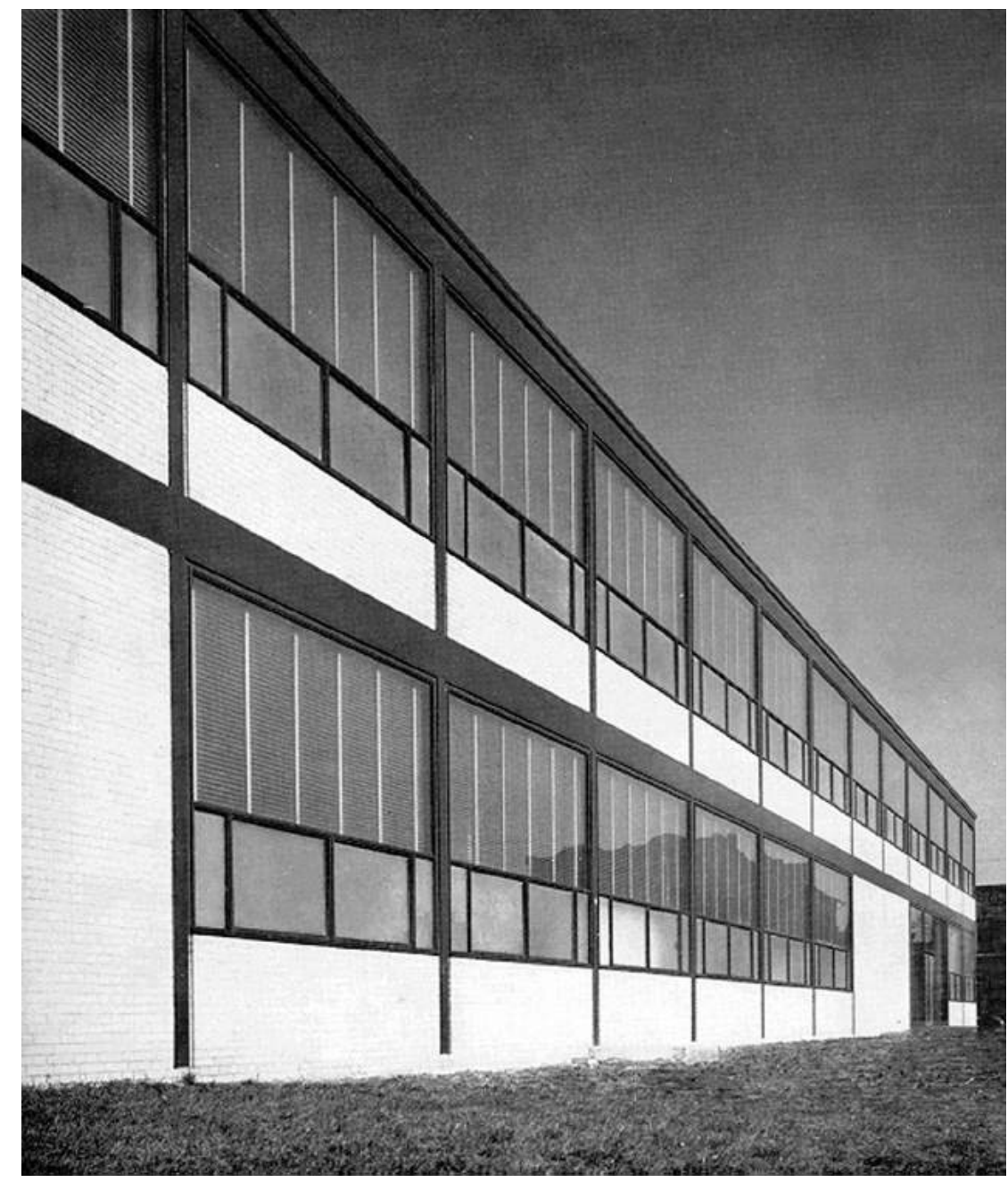




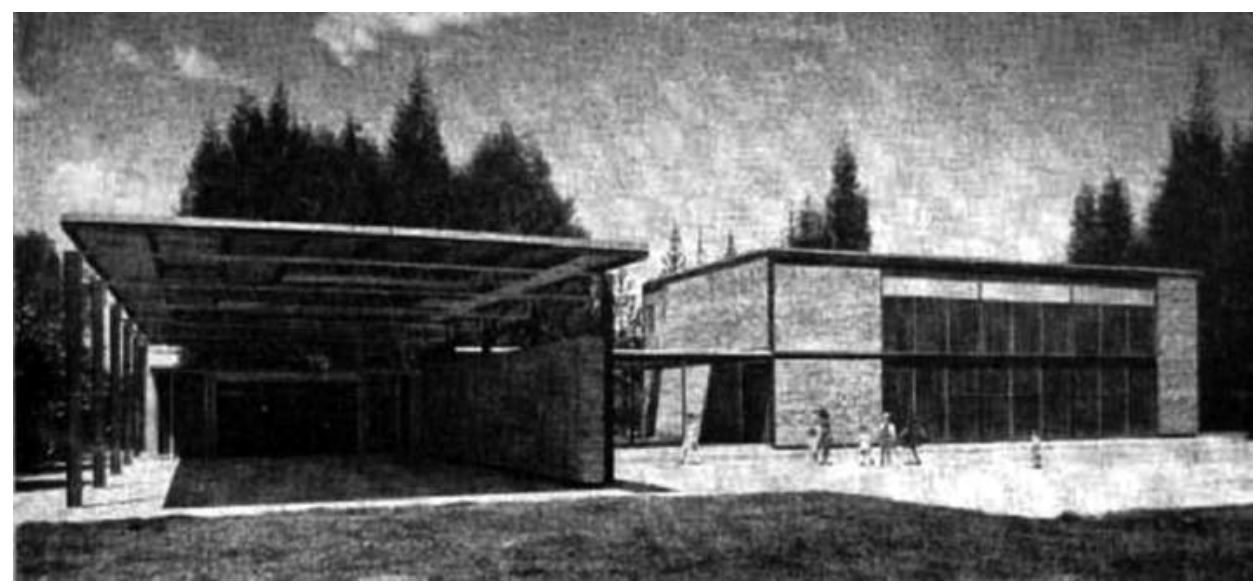

Figura 3. Robledo, Drews y Castro. (1955). Refugio y teatro infantil. Fuente: Martínez Carlos. (1956). Refugio y teatro infantil en el Club los Lagartos. Proa, 97, p.4.

Los materiales de proyecto, como se planteó en principio, como lo afirma Piñón (2006, p. I30) son: "elementos o soluciones avalados por la historia y la experiencia" los cuales se constituyen en la materia prima del proyecto.

El objetivo principal como herramienta proyectual es brindar una estructura formal a la capacidad ordenadora de quien proyecta, su implementación resalta la capacidad formadora del proyecto, por lo tanto, se aprende mientras se proyecta, además se compromete en superar el punto de partida para que resulte el proyecto distinto al de la materia prima empleada, es decir, auténtico. En el Refugio y Teatro Infantil del Club Los Lagartos (1955), se hace claro el uso de la referencia del Alumni Memorial hall en Chicago proyectado por Mies Van der Rohe en 1946, sin embargo, el objeto arquitectónico resultado conserva su autenticidad, es decir, no termina siendo una "copia" literal del punto de partida. (Ver Figuras 2 y 3). Un ejemplo actual que valida su vigencia como herramienta proyectual es la casa en Caparicuiba (2003) de Angelo Bucci que emplea criterios de la casa en Butanta (1964) de Paulo Mendes da Rocha. (Ver Figuras 4 y 5 ).
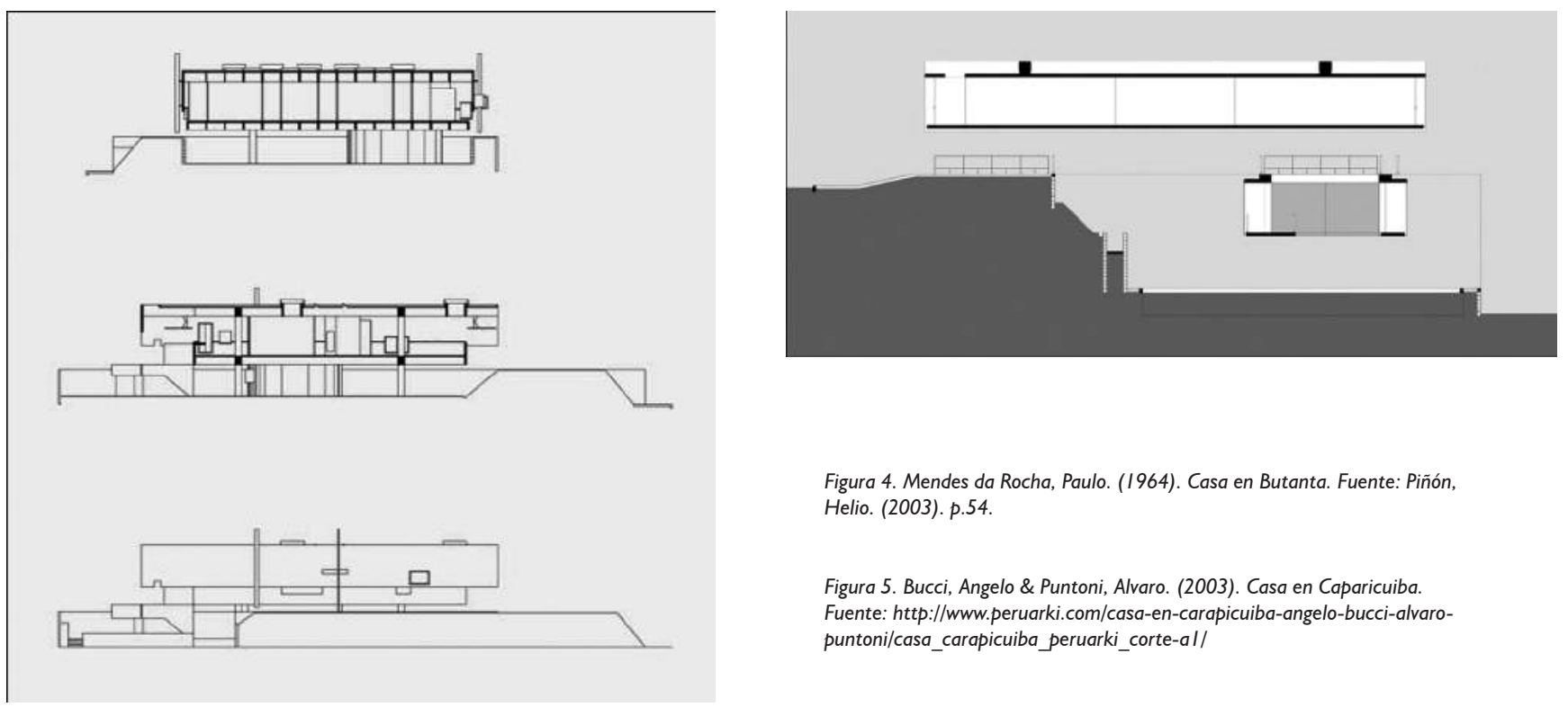

Figura 4. Mendes da Rocha, Paulo. (1964). Casa en Butanta. Fuente: Piñón, Helio. (2003). p.54.

Figura 5. Bucci, Angelo \& Puntoni, Alvaro. (2003). Casa en Caparicuiba. Fuente: http://www.peruarki.com/casa-en-carapicuiba-angelo-bucci-alvaropuntoni/casa_carapicuiba_peruarki_corte-al/ 
Figura 6. Van der Rohe, Mies. (1945-1950). Casa Farnsworth. Fuente: http://www.urbipedia.org/ images/6/64/Casa_farnsworth-planta.jpg

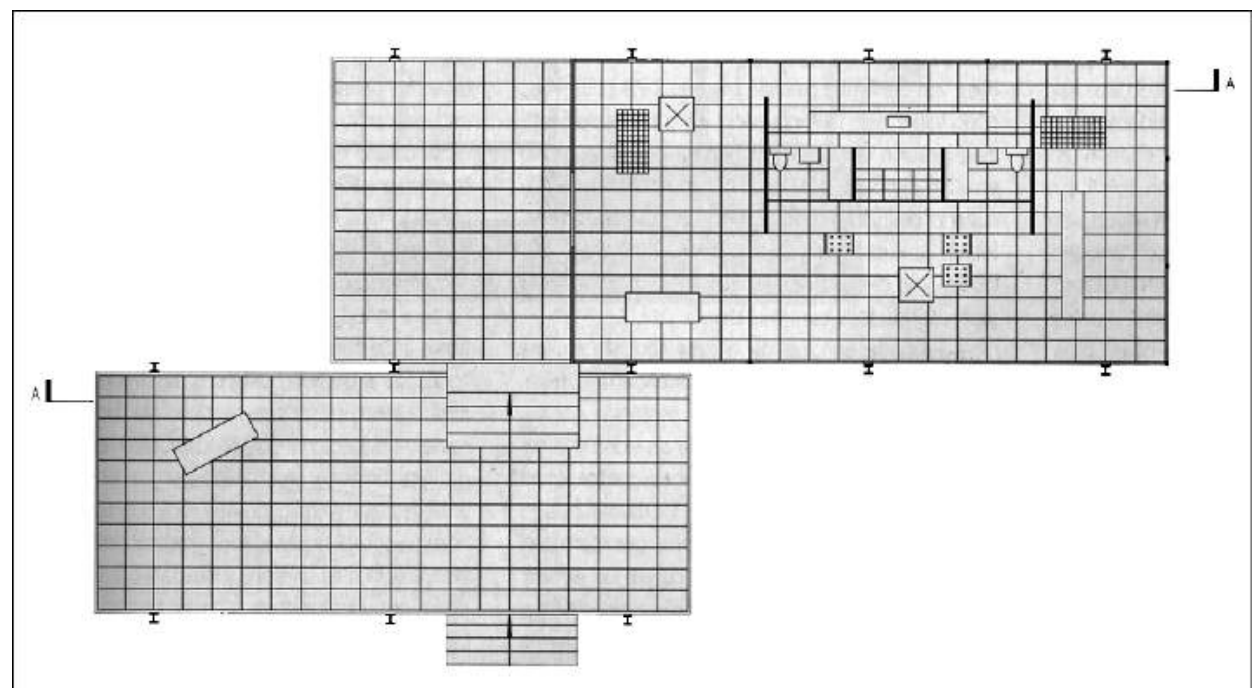

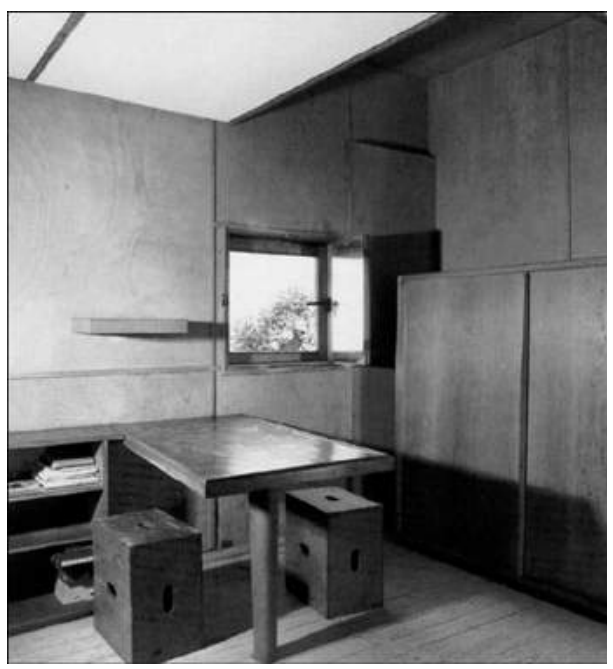

Figura 7. Le Corbusier. (1952). Cabaña de vacaciones Fuente: $h$ ttp://www.ymag.it/schede.asp?id=1524

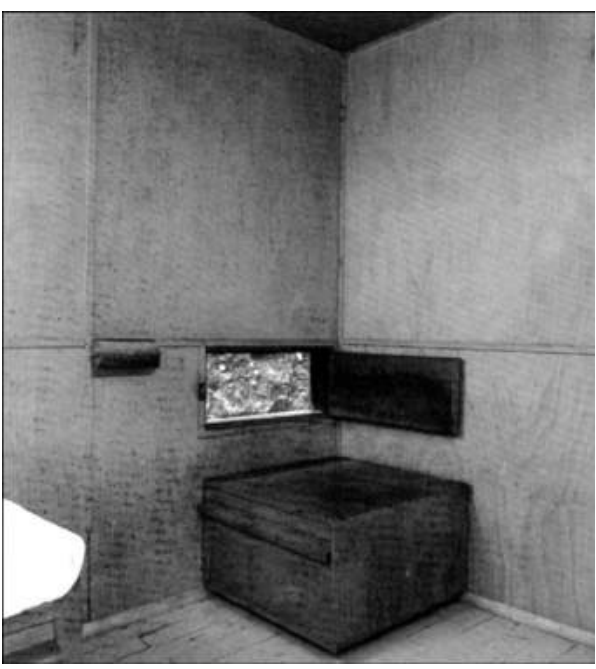

Figura 8. Le Corbusier. (1952). Cabaña de vacaciones Fuente: http://www.ymag.it/schede.asp?id=1524
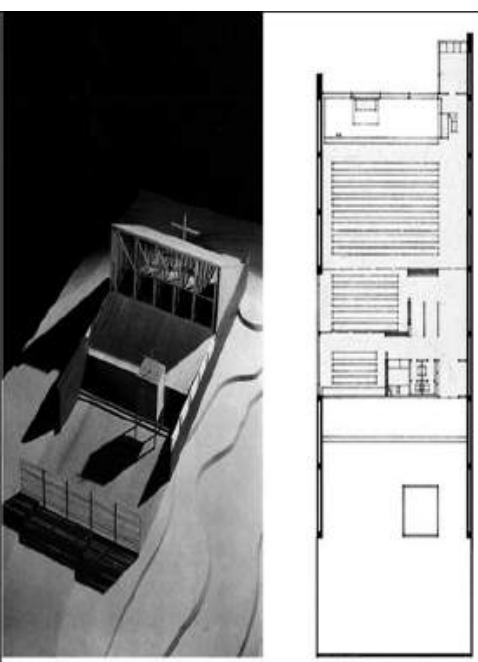

Figura 9. Siren, Kaija \& Heikki. (1957). Capilla en Otaniemi. Fuente: Piñón Helio. (2005). p.88.

Los materiales de proyecto dentro del marco estético moderno y para definirse como tales, presentan unos valores visuales y unos criterios formales específicos que permiten identificarlos y actuar sobre ellos.

\section{Valores visuales}

Como valores visuales se entienden aquellos valores que se pueden identificar en el objeto una vez proyectado, bien de manera parcial o de manera definitiva, los cuales permitirían re-conocer los atributos que a principio de siglo XX Le Corbusier y A. Ozenfant (Citado en Piñón 2006) propusieron como atributos del arte moderno: "la economía, el rigor, la precisión y la universalidad".

\section{La economía}

Se entiende como el uso del menor número de elementos para configurar el mayor número de relaciones formales, funcionales y técnicas necesarias, Como ejemplo se muestra la casa Farnsworth de Mies Van der Rohe proyectada entre 1946 y 195 I, donde la isla de servicios estructura la mayoría de relaciones al interior de la vivienda. (Ver Figura 6). 


\section{El rigor}

Entendido como la implementación consecuente de los criterios formales en todas las escalas del objeto, Tal como se puede apreciar al interior de la cabaña de vacaciones de Le Corbusier proyectada en 1952, donde el rigor alcanza el detalle tanto de los cerramientos como en el mobiliario haciendo parte todo de un conjunto equilibrado. (Ver Figuras 7 y 8 ).

\section{La precisión}

Entendido como la medida justa, ni más elementos que propicien el despilfarro ni la escasez premeditada de elementos como recurso estilístico o de maquillaje de lo mínimo, este valor de entrada exige criterio por parte de quien proyecta como se puede ver en la Capilla en Otamieni de los Arquitectos Kaija Siren \& Heikki. (Ver Figura 9).

\section{La universalidad}

Entendida como lo esencial de lo que cada configuración entre los elementos constitutivos del objeto arquitectónico puede llegar a ser. En el proyecto de la casa Adler de Louis Kahn de 1954 la estructura formal portante estimula al espectador el abstraer a una realidad reconocible por el sentido común la figura geométrica básica del cuadrado. (Ver Figura l0).

Estos valores visuales igualmente permiten re-conocer el equilibrio de los artefactos a partir de equivalencias y no necesariamente, en el sentido clásico, a partir de igualdades. Un ejemplo de esto lo plantea la casa de Ciudad de Vaticano del arquitecto Emilio Duhart, donde la tensión entre los elementos, diferenciados y relacionados entre sí que constituyen el artefacto, es lo que visualmente estructura el proyecto. (Ver Figura II).

En definitiva estos valores, como resultado del proyecto, se constituirán como el marco del juicio estético de quien se enfrente a la obra.

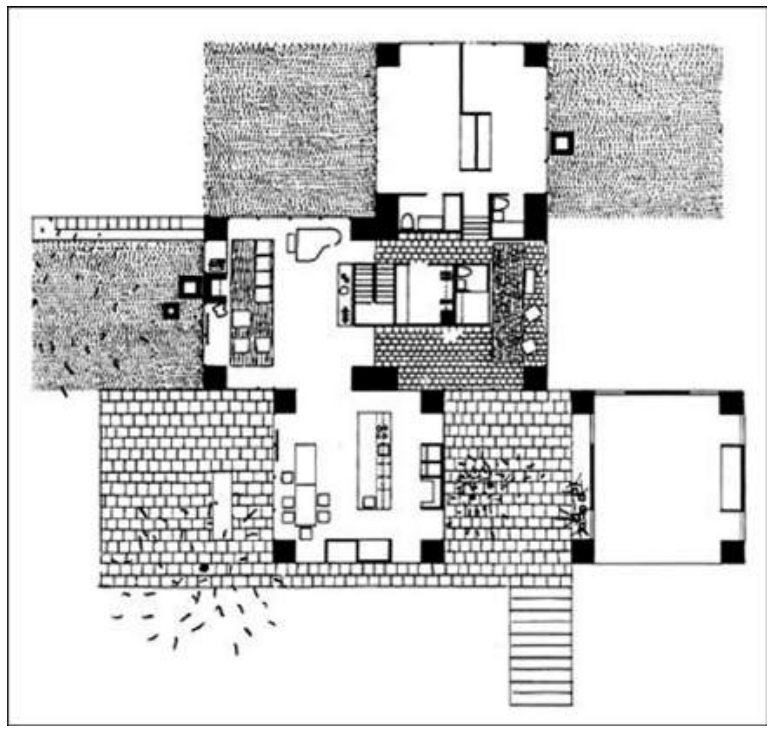

Figura 10. Kahn, Louis. (1954). Proyecto casa Adler. Fuente: Piñón Helio. (2005). p.37.

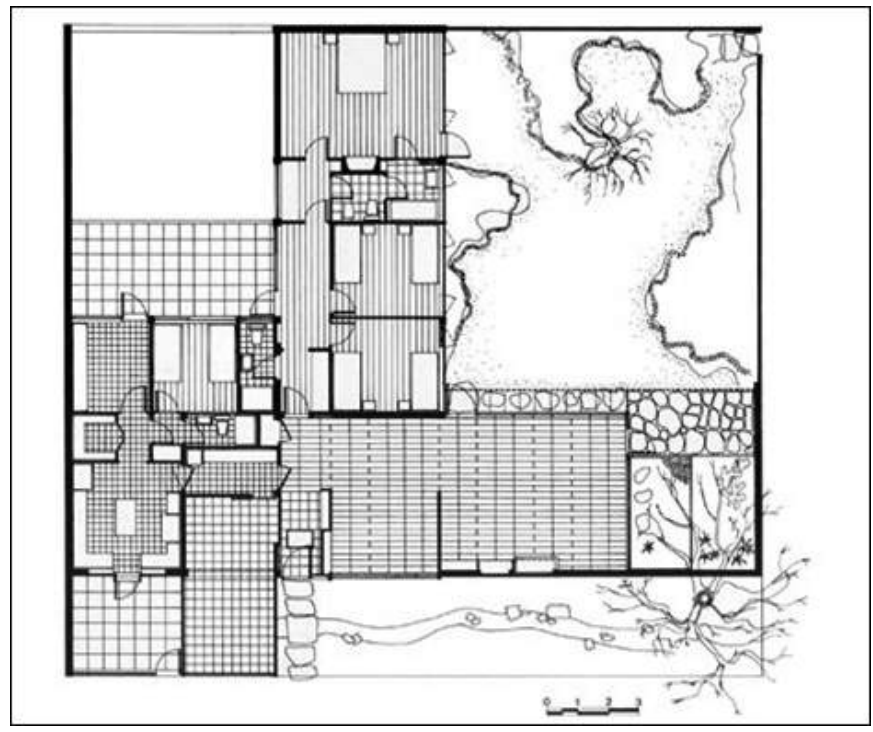

Figura II. Duhart, Emilio. (1944). Casa c/ del Vaticano. Fuente: Piñón Helio. (2005). p.80. 


\section{Criterios formales}

Por otro lado los criterios formales son las decisiones de quien proyecta, basadas sobre los principios estéticos de la modernidad, es decir; la concepción resultado de las problemáticas que surgen de la relación entre el programa requerido y el contexto histórico-geográfico determinado de cada objeto, lo que en definitiva es lo que lo dota de identidad, la abstracción como modo de asumir lo esencial en la configuración del proyecto y por último la forma consistente es decir la identificación como una unidad en la cual el sistema constructivo condiciona sus posibilidades formales. Ejemplo de la adaptación de estos criterios se aprecia (I987-1994) en la tienda Forma proyectada por Paulo Mendes da Rocha. (Ver Figura I2).

Figura I2. Mendes da Rocha, Paulo. (19871994). Tienda Forma. Fuente: Piñón Helio. (2005). p. 103

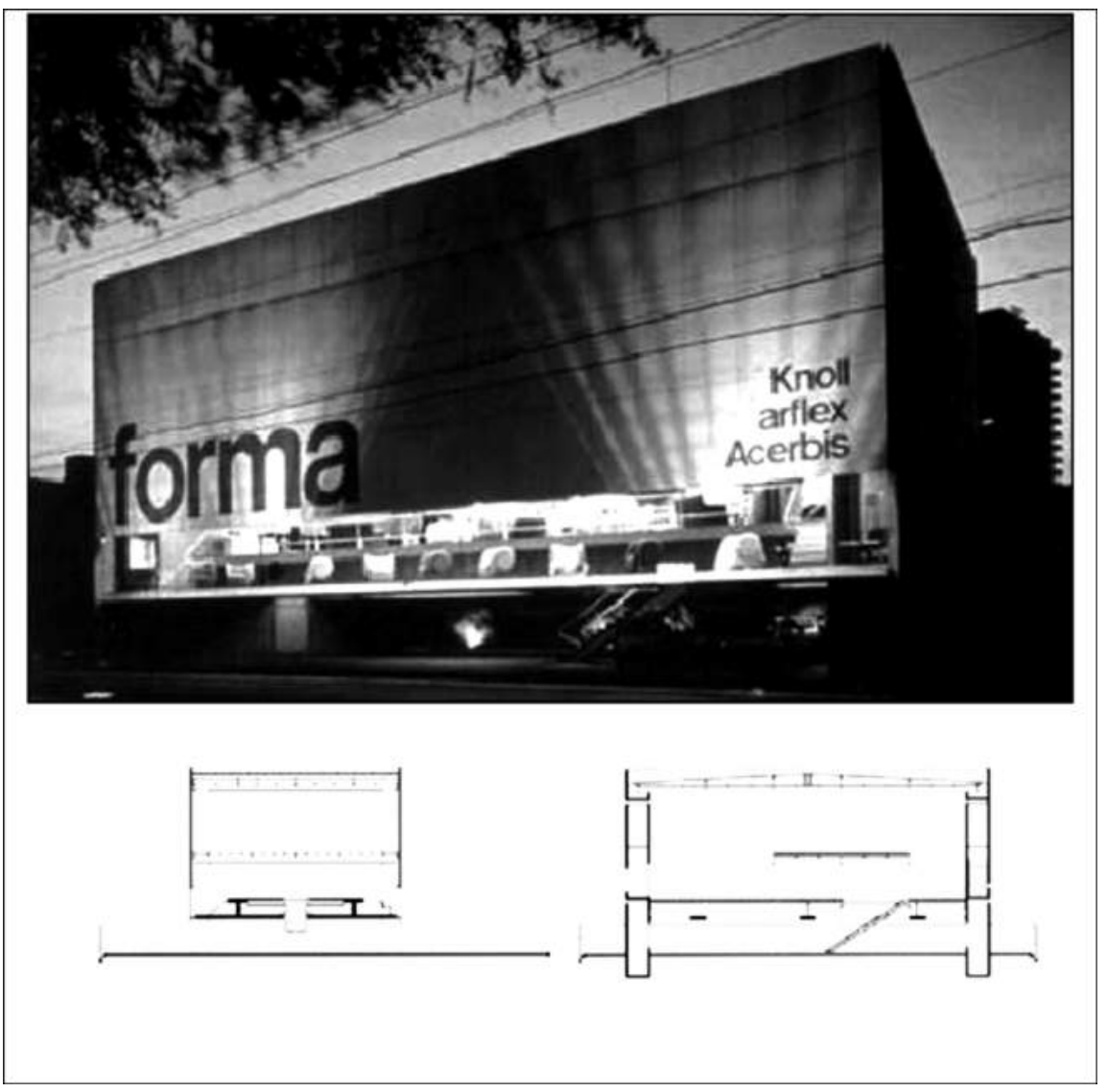

\section{Metodología}

La metodología propuesta plantea el análisis del objeto de estudio y su posterior síntesis a partir de un método que propone las siguientes actividades como las necesarias para los fines establecidos: primero, la definición del objeto de estudio; segundo, la recolección material de investigación necesario; tercero, la edición y tratamiento de dicho material; cuarto, el análisis propiamente dicho $y$, por último, la síntesis que en definitiva es la que plantea el reconocimiento de los criterios formales y valores visuales validados como Materiales de Proyecto en el Refugio y teatro infantil. 


\section{Desarrollo}

\section{Definición del objeto de estudio}

Para la selección del objeto de estudio se tomó la intuición como una herramienta afinada y precisa, para lo cual se necesitó una lectura continua y profunda de la forma moderna, entendida no como un objetivo en sí, sino como un ejercicio de síntesis de un conjunto de soluciones a las problemáticas que surgen del binomio programa-contexto. Dentro de este marco, luego de una mirada intensiva, aplicada la intuición y la experiencia en la lectura de proyectos por parte del equipo investigador, se definió el Refugio y teatro infantil del club los Lagartos dentro de un grupo proyectos ${ }^{3}$ como los indicados para aplicarles la metodología de análisis y posterior validación de sus criterios formales y valores visuales como materiales de proyecto.

\section{Recolección material de investigación}

La investigación pudo recopilar la siguiente documentación correspondiente al proyecto del Refugio y Teatro infantil. (Ver Tabla I).

Tabla I. Obra proyectada RDC arquitectos. 1954-1960.

\begin{tabular}{|c|c|c|c|c|c|c|c|c|c|}
\hline \multirow{2}{*}{ 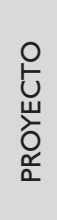 } & \multirow{2}{*}{$\begin{array}{l}\stackrel{\mathrm{J}}{\mathrm{u}} \\
\stackrel{\mathrm{U}}{\vec{U}}\end{array}$} & \multirow{2}{*}{ 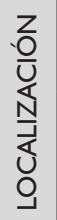 } & \multirow{2}{*}{$\begin{array}{l}\text { 㥑 } \\
\text { 出 }\end{array}$} & \multirow{2}{*}{ 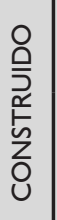 } & \multirow{2}{*}{$\begin{array}{l}\text { 㟧 } \\
\text { O } \\
\frac{5}{2}\end{array}$} & \multicolumn{3}{|c|}{ DOC. } & \multirow{2}{*}{$\begin{array}{l}\frac{Z}{\mathrm{U}} \\
\frac{\mathrm{v}}{\mathrm{o}}\end{array}$} \\
\hline & & & & & & Perspectivas & Fotografías & Plano & \\
\hline \multirow{10}{*}{ 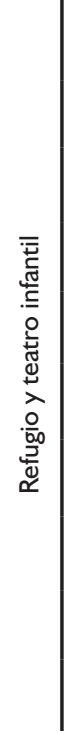 } & \multirow{10}{*}{ 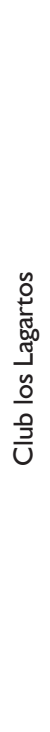 } & \multirow{10}{*}{ 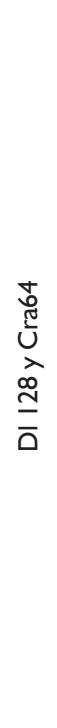 } & \multirow{10}{*}{$\begin{array}{l}\frac{\tilde{\alpha}}{\alpha} \\
\frac{\tilde{\sigma}}{\tilde{w}}\end{array}$} & \multirow{10}{*}{ is } & \multirow{10}{*}{ 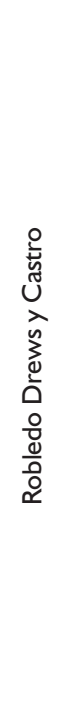 } & $\begin{array}{l}\text { I. Vista general } \\
\text { fachada este }\end{array}$ & & & $\begin{array}{l}\text { PROA } \\
97-100\end{array}$ \\
\hline & & & & & & & $\begin{array}{l}\text { 2.Vista Interior } \\
\text { Refugio Infantil }\end{array}$ & & PROA 97 \\
\hline & & & & & & & $\begin{array}{l}\text { 3. Vista conjunto } \\
\text { fachada este }\end{array}$ & & $\begin{array}{l}\text { PROA } \\
97-384\end{array}$ \\
\hline & & & & & & & $\begin{array}{l}\text { 4. Vista conjunto } \\
\text { fachada norte }\end{array}$ & & PROA 97 \\
\hline & & & & & & & $\begin{array}{l}\text { 5. Vista interior } \\
\text { teatro } \\
\end{array}$ & & PROA 97 \\
\hline & & & & & & & & $\begin{array}{l}\text { 6. Planta } \\
\text { General }\end{array}$ & $\begin{array}{l}\text { PROA } \\
97-384\end{array}$ \\
\hline & & & & & & & & $\begin{array}{l}\text { 7. Planta de } \\
\text { localización }\end{array}$ & PROA 97 \\
\hline & & & & & & & & $\begin{array}{l}\text { 8. Cortes y } \\
\text { fachadas }\end{array}$ & $\begin{array}{l}\text { Beatriz } \\
\text { García' }\end{array}$ \\
\hline & & & & & & & & 9. Plantas & $\begin{array}{l}\text { Beatriz } \\
\text { García }\end{array}$ \\
\hline & & & & & & & & 10. Detalles & $\begin{array}{l}\text { Beatriz } \\
\text { García }\end{array}$ \\
\hline
\end{tabular}

3 I. Refugio y teatro infantil del Club Los Lagartos (1955), 2. Residencia para Alonso Londoño (1957), 3. Tres residencias para Alberto Lotero (1956), 4. Residencia para Carlos Ángel Villa (1958), 5. Edificio para Jorge Nalús, 6. Residencia para Emilia Zuleta Calderón (1956), 7. Residencia para Fernando Restrepo (1956), 8. Residencia y 9. Estudio para Pedro Celis (1956). Estas obras se seleccionaron por su relevancia y potencial para validar sus criterios formales y valores visuales como material de proyecto. El alcance del proyecto de investigación dejó definidos los últimos 7 proyectos como futuros objetos de estudio, que forman parte del banco de proyectos de investigación del Grupo de Investigaciones de la Facultad de Arquitectura de la Universidad Santo Tomás. 


\section{Edición y tratamiento del material}

La investigación confirmó que el redibujo es una herramienta potente de análisis y comprensión del artefacto arquitectónico, ya que, como lo afirma Gastón y Rovira (2007. p. 19):

El delineado obliga a mirar y a interrogarse acerca de aspectos físicos concretos del edificio y aleja la posibilidad de divagar. Permite tomar conciencia de las dimensiones del edificio y de sus componentes, de la jerarquía de trazados, de modulaciones ordenadoras, de la relación entre elementos constructivos.

Así mismo este proceso, permite realizar las mismas preguntas a las cuales los arquitectos se enfrentaron a la hora de proyectar, que potenciaron de esta forma la posibilidad de comprensión del objeto.

\section{Análisis}

Para el presente análisis se tomó como referencia metodológica lo planteado por Gastón y Rovira (2007 p.28), cuestión que permitió llegar a los pormenores del Refugio y Teatro infantil tanto en términos constructivos como proyectuales, estos son la base a partir de la cual se validaron los criterios formales y valores visuales como material de proyecto.

\section{Refugio y Teatro Infantil en el Club Los Lagartos 1955}

El siguiente análisis corresponde al proyecto de Refugio y Teatro Infantil para el Club Los Lagartos proyectado y construido por Robledo, Drews y Castro Arquitectos entre los años 1955 y 1956.

\section{Emplazamiento y programa}

Posición del terreno en la ciudad, calles que lo rodean, posibilidades de acceso, características de las vecindades.

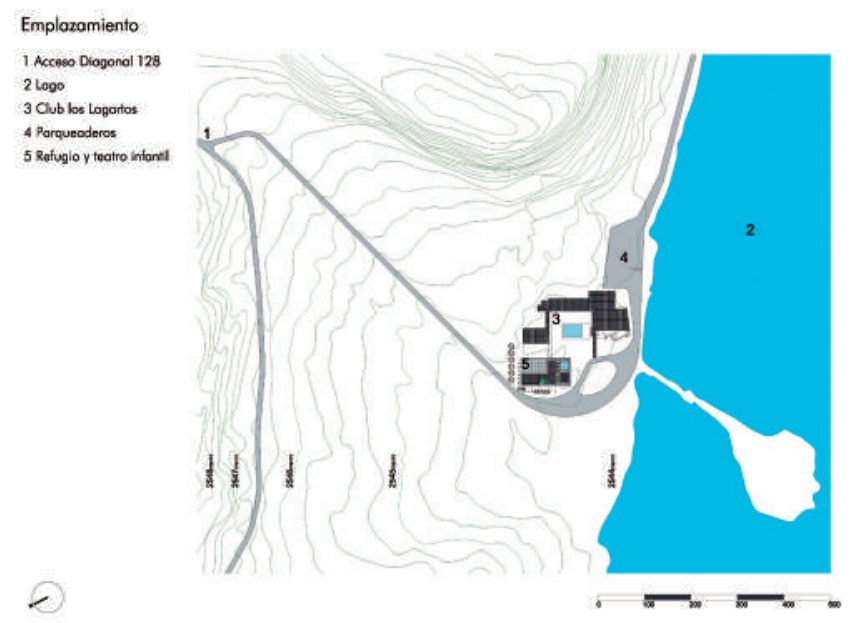

Figural3.

Fuente: Elaborado por Mario Narváez Salas.

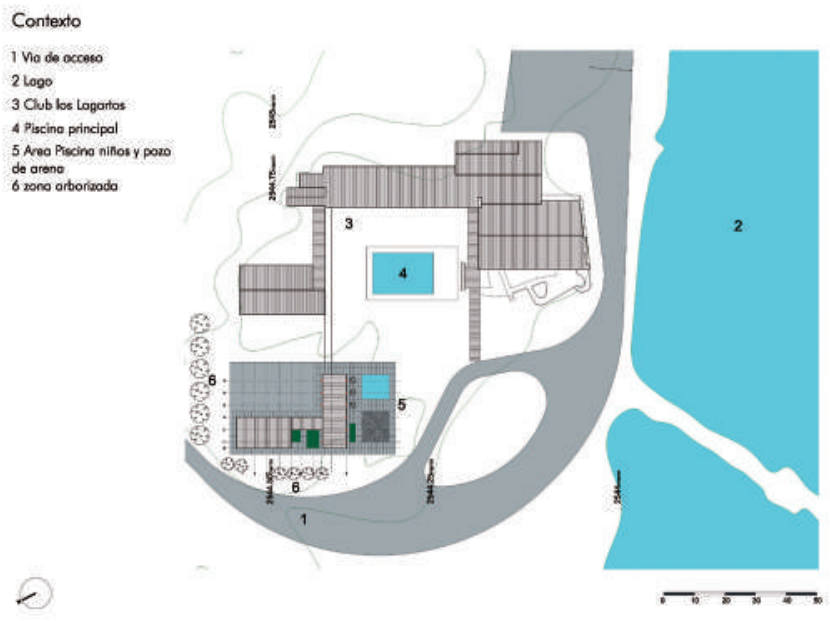

Figura 14.

Fuente: Elaborado por Mario Narváez Salas. 
El terreno donde se emplaza el proyecto de Refugio y teatro infantil se ubica dentro de la propiedad del Club Los Lagartos, proyecto diseñado y construido en 1946 por la firma Cuéllar Serrano Gómez al noroccidente de la ciudad de Bogotá, en una zona de carácter campestre a la cual se accede por la diagonal I 28 con carrera 64, ver Figura I3. El proyecto en referencia es bordeado sobre el norte y el occidente por la vía de acceso principal al Club y una zona verde arborizada a partir de pinos de aproximadamente $12 \mathrm{~m}$ de altura. Sobre el sur se vincula con la zona de la piscina de niños y el pozo de arena y, por último, sobre el costado oriental se abre hacia el edificio principal del Club Campestre, es esta la única edificación existente en su momento y de la cual el proyecto de Refugio y Teatro Infantil es una ampliación, ver Figura 14. Esta disposición de volúmenes en campo abierto hace recordar varios de los objetos dispersos pero ordenados que se encuentran en el Campus del Illinois Institute of Technology del Arquitecto Mies Van der Rohe proyectado desde 1942 hasta 1947, (ver Figura 15), la capilla St. Savior (1949-52) y el edificio del Alumni-Memorial-Hall (1945-46) son referencias claras para los arquitectos, tal y como lo afirma Villamizar (2009): "El proyecto se encuentra basado totalmente en la obra del arquitecto alemán Mies van Der Rohe y surge en el periodo posterior a la permanencia del arquitecto Dicken en Estados Unidos” (p.3.), ver Figura 16.
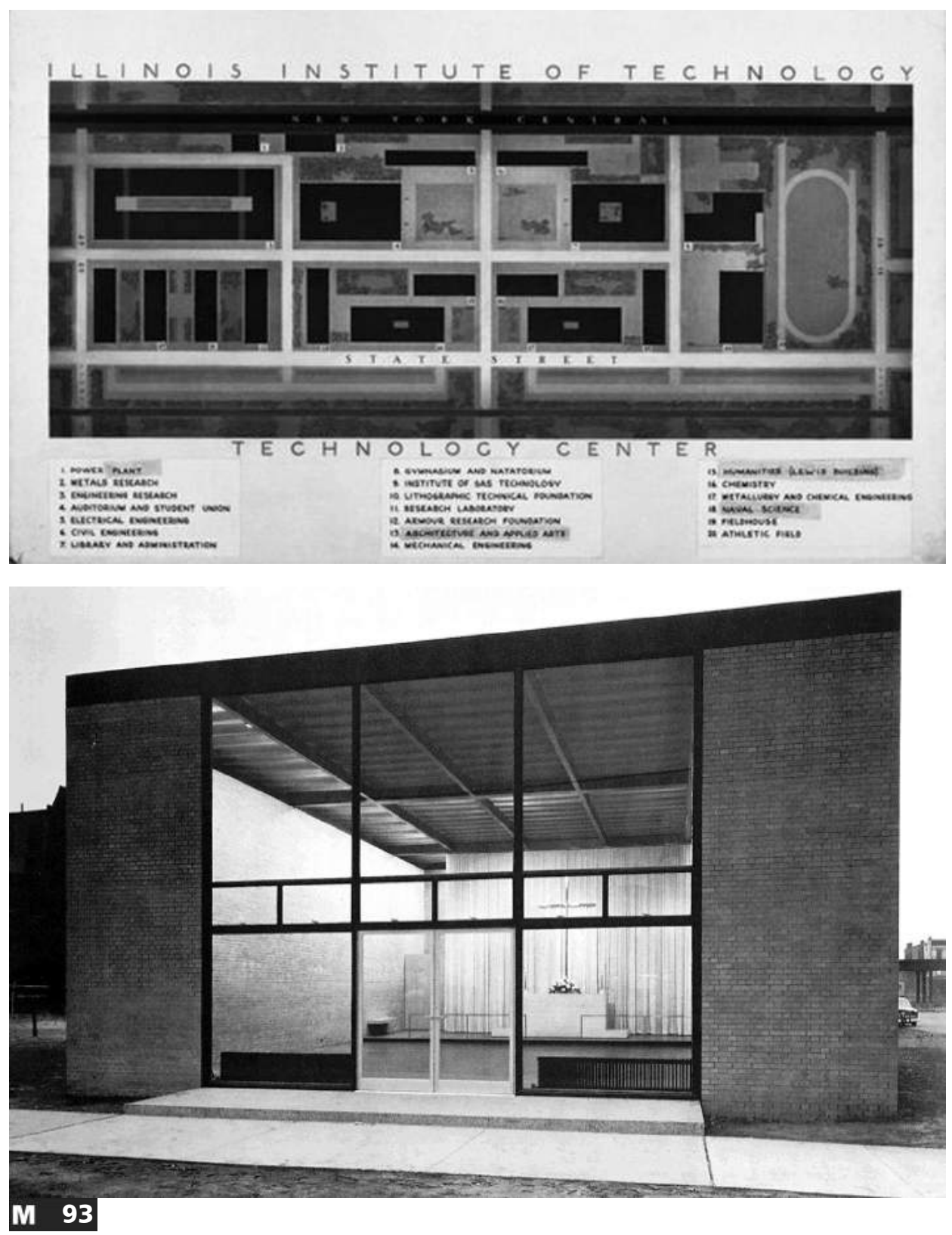

Figura 15. Van der Rohe, Mies. (1945-46). IIT Master Plan. Fuente: http://www.moma. org/collection/object.php?object_id $=873 / 4$

Figura 16. Van der Rohe, Mies. (1949). ITT, Chicago: Kapellle St. Savior. Fuente: http:// www.ruhr-uni-bochum.de/kgi/projekte/ rub_expo/k5/tbu3a5.gif 
Extensión en superficie, dimensiones y geometría del perímetro, condiciones de los lindes

El área aproximada del terreno en donde se emplaza el proyecto es de $1620 \mathrm{~m}^{2}$ con una geometría regular - $54 \mathrm{~m}$ de largo por $40 \mathrm{~m}$ de ancho- con linderos abiertos, producto de ser un edificio anexo dentro del club. Debido a esto las dimensiones específicas del terreno El Refugio y Teatro en términos de límites se enlazan con las del terreno general del Club por lo que el proyecto se desarrolla como un ejercicio de entretejer el tejido existente.

Topografía, presencia de construcciones o vegetación (tipo, altura, densidad). Condiciones climáticas relevantes: orientación solar, rango de temperaturas, régimen de lluvias o vientos, sismicidad.

La topografía del terreno donde se emplaza el proyecto es básicamente plana con una pendiente mínima en sentido sur que se dirige hacia el lago del Club, elemento que se constituye en la visual predominante del lugar y hacia la que el Refugio se proyecta, para integrar el contexto geográfico del Club a manera de un plano de fondo en la composición de sus visuales, ver Figura 17.

La única construcción existente es el edificio del Club. Éste presenta dos niveles generados por volúmenes adosados que configuran un patio interno en donde se emplaza la piscina principal y sobre el cual el proyecto se vincula desplazándose y para completar el cerramiento que define materialmente dicho patio al mismo tiempo que configura uno nuevo alrededor de la pista de patinaje y logra a pesar de ser un proyecto independiente, integrarse tanto al contexto geográfico como al contexto construido, ver Figura 18.

Las masas principales de vegetación, que en su mayoría son pinos adultos de $12 \mathrm{~m}$ de alto, se encuentran localizadas sobre los costados occidental y norte del proyecto, convirtiéndose en un segundo plano que tensiona las fachadas este y sur, fachadas que se constituyen como las principales del proyecto, ver Figura 19.

El sentido de la orientación general del proyecto es norte-sur con un clima que alcanza una temperatura promedio de 14 grados centígrados, con lluvias moderadas y vientos predominantes provenientes del norte. Por otra parte, y como otra de las particularidades a las que se enfrenta el proyecto, se encuentra la amenaza de riesgo sísmico intermedia debido a la ubicación geográfica sobre las cordilleras central y oriental.

Programa funcional que el edificio tenía que acoger: superficies totales y parciales, relación de los usos previstos, características y correlaciones.

El programa funcional que alberga el proyecto se divide en dos partes: la primera es un espacio cubierto para juegos, con fuente de soda y vestieres; la segunda es una sala múltiple para cine y gimnasio infantil. El proyecto tiene una superficie total de $365 \mathrm{~m}^{2}$, de los cuales $190 \mathrm{~m}^{2}$ corresponden al teatro y $175 \mathrm{~m}^{2}$ al refugio, ver Tabla 2. 


\section{Contexto}

1 Logo

2 Edificio Club los logartos

3.a Refugio infantil

3.b Teatro

4 Area Piscina niños y pozo

de arena

5 zona orborizoda

Vista del lago desde la zona cubierto de juegos del refugio infantil
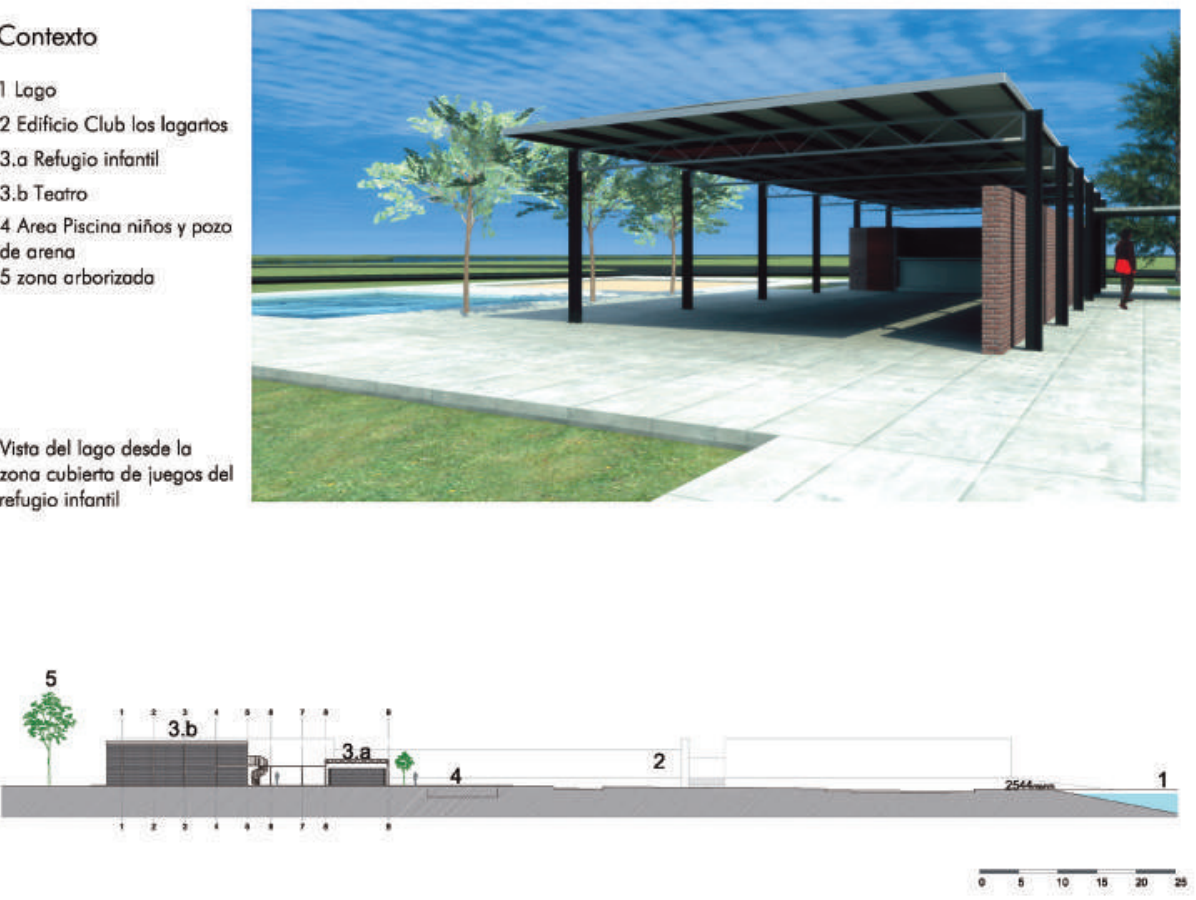

Construcciones

existentes

Vista aérea del proyecto con

relacion al los edificios

exixtentes
Figura 17. Fuente: Elaborado por Mario Narváez Salas.
Figura 18. Fuente: Elaborado por Mario Narváez Salas.

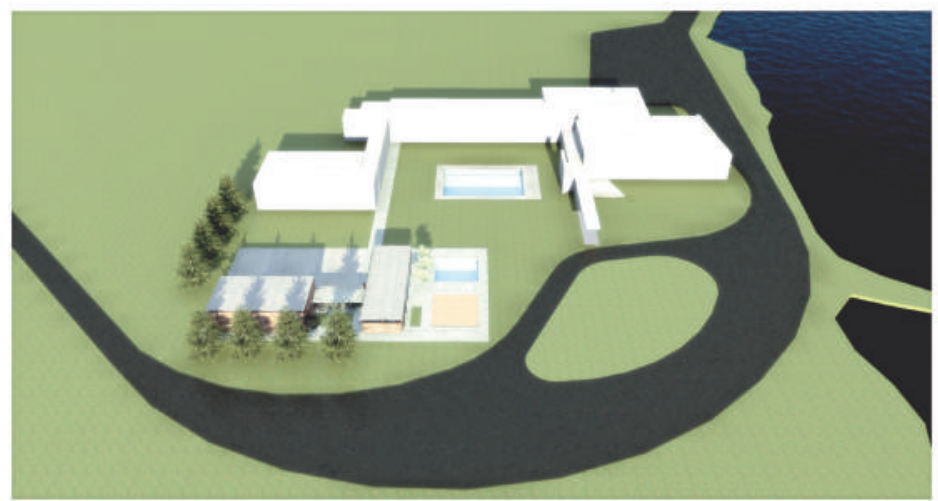


Figura 19. Fuente: Elaborado por Mario Narváez Salas.

\section{Fachadas principales}

Fachada Este

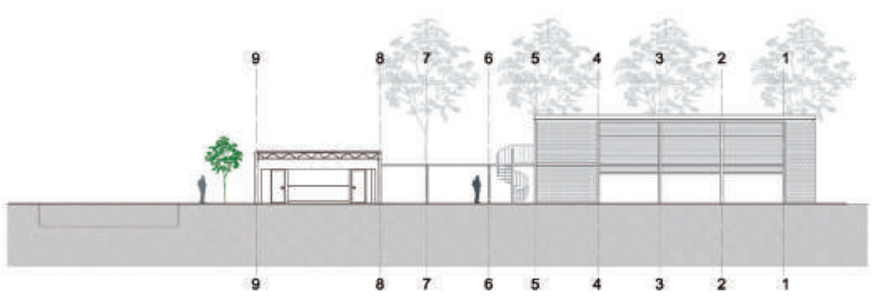

Fachada Sur

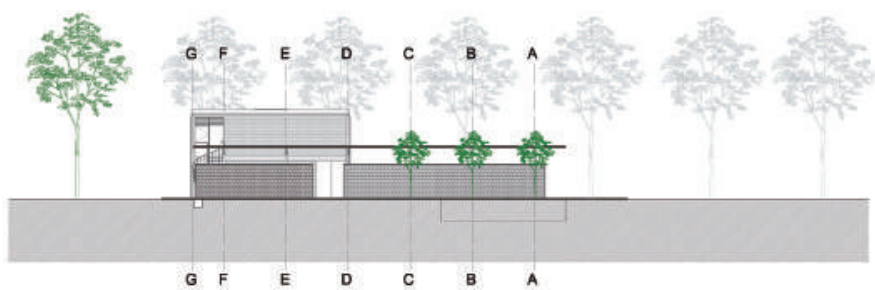

$-\overline{25}-5-7$

Figura 20. Fuente: Elaborado por Mario Narváez Salas.

Planta General

1 Sala múltiple

2 Deposito

3 Zona cubierta para juegos

4 Fuente de sodo

5 Vestieres

6 Pasarela

7 Pista de potinaje

8 Piscina niños

9 Pozo de arena

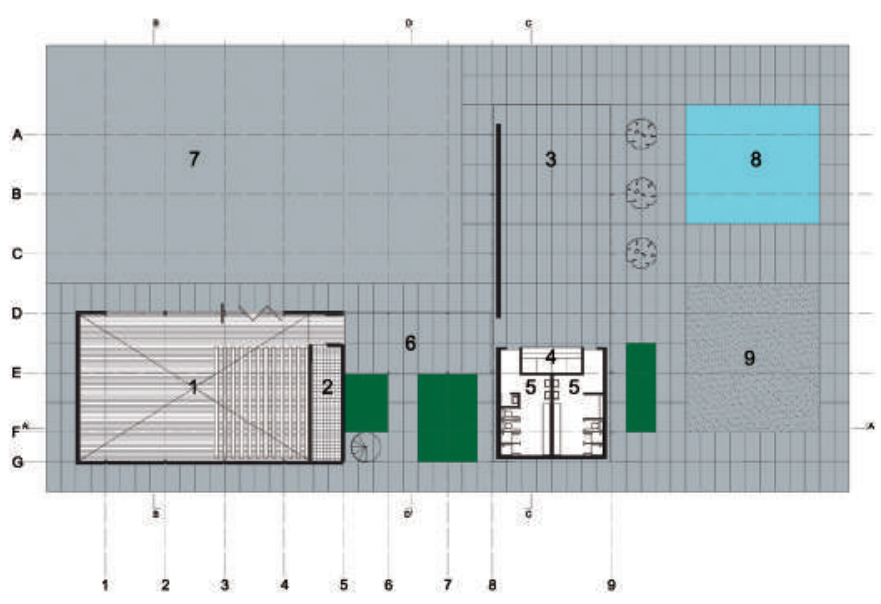

(2)

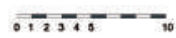


Tabla 2. Cuadro de áreas Refugio y Teatro infantil

\begin{tabular}{|l|c|}
\hline \multicolumn{2}{|c|}{ TEATRO INFANTIL } \\
\hline Sala múltiple & $155 \mathrm{~m}^{2}$ \\
\hline Depósito & $15 \mathrm{~m}^{2}$ \\
\hline Cuarto de proyecciones & $20 \mathrm{~m}^{2}$ \\
\hline Total teatro & $190 \mathrm{~m}^{2}$ \\
\hline \multicolumn{2}{|c|}{ REFUGIO } \\
\hline Zona cubierta para juegos PASARELA CUBIERTA & $127 \mathrm{~m}^{2}$ \\
\hline Fuente de soda & $7 \mathrm{~m}^{2}$ \\
\hline Vestieres & $41 \mathrm{~m}^{2}$ \\
\hline Total área refugio & $175 \mathrm{~m}^{2}$ \\
\hline \multicolumn{2}{|c|}{} \\
\hline Área Cubierta & $42 \mathrm{~m}^{2}$ \\
\hline TOTAL REFUGIO Y TEATRO INFANTIL & $407 \mathrm{~m}^{2}$ \\
\hline
\end{tabular}

El uso previsto de los espacios dota al proyecto de un edificio independiente para los niños el cual complementa las actividades del edificio principal. Por su parte, el teatro se abre sobre el costado este hacia la zona exterior de la pista de patinaje -espacio que al mismo tiempo es un auditorio al aire libre- $y$, sobre el costado sur hacia el refugio a través de una pasarela cubierta, contrario a lo que sucede sobre el costado oeste en donde el teatro se cierra sobre la vía de acceso principal al igual que lo hace el edificio del Refugio al ubicar el módulo de vestieres y fuente de soda. Así como el teatro se abre sobre la pista de patinaje el refugio se cierra sobre la misma a partir de un muro que sirve para controlar los vientos predominantes provenientes del norte y proteger las actividades hacia las cuales el refugio se proyecta: la piscina y el pozo de arena, ver Figuras 20 y 21.

El teatro se relaciona con el refugio a través una estructura cubierta independiente que configura la pasarela antes mencionada, la cual análogamente se proyectó para conectar los edificios del teatro y refugio con el edificio principal, a partir de la zona cubierta de juegos del refugio, cuestión que finalmente no se llevó a cabo en la construcción definitiva. Sin embargo, constituía un elemento de relación importante al continuar con la noción de diferenciar, relacionar y tensionar los elementos que pretendía articular, ver Figura 22.

Planta Segundo piso

Figura 2I. Fuente: Elaborado por Mario Narváez Salas.
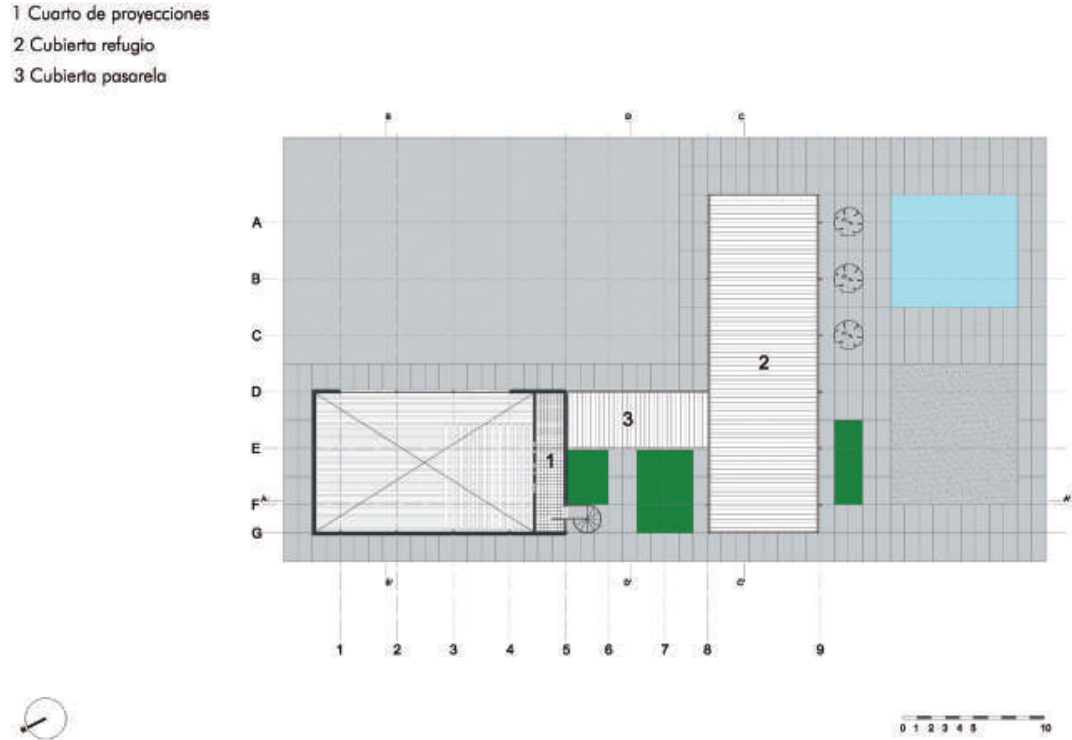
Figura 22. Fuente: Archivo Beatriz García

\section{Pasarela}

Pasarela proyectada para

comunicar el edificio principa

con el refugio y teatro infantil

(no construida)

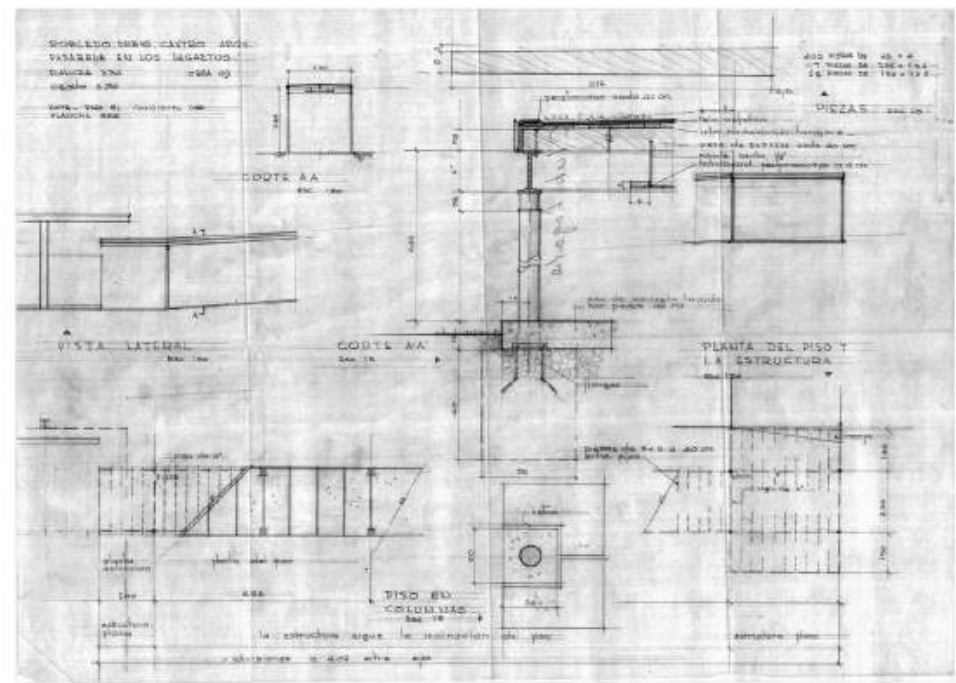

Figura 23. Fuente:Mario Narváez Salas.

\section{Volumenes}

Vista de los volumenes

principoles, a la izquierda

volumenn del refugio y a lo

derecha el volumendel teatro

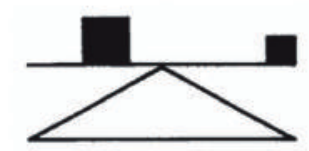

Posibilyty of "balance dissimilar weights by shiffing their position *

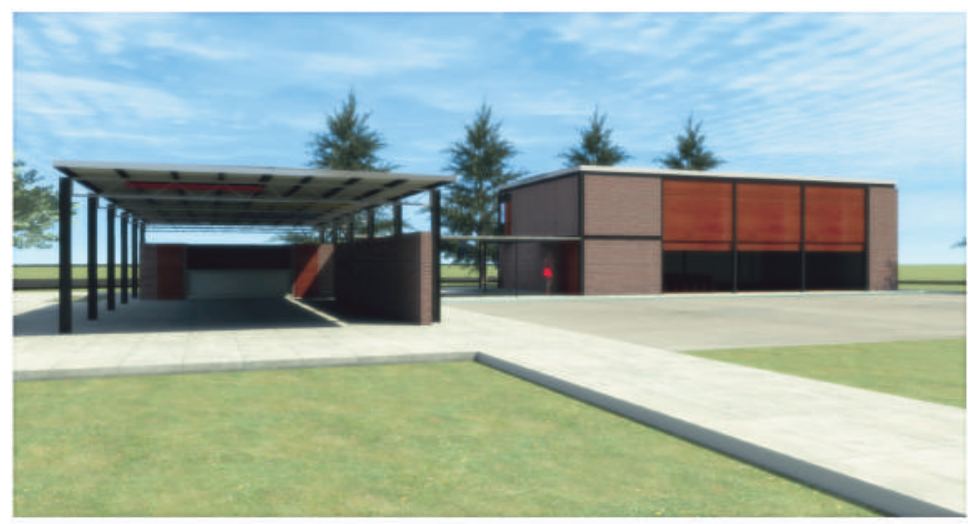




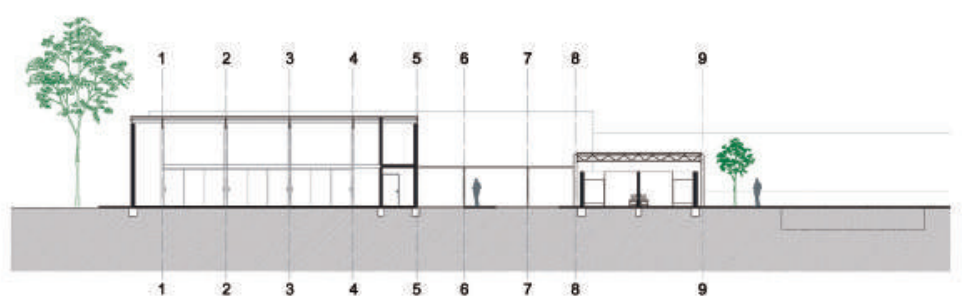

Corte C-C

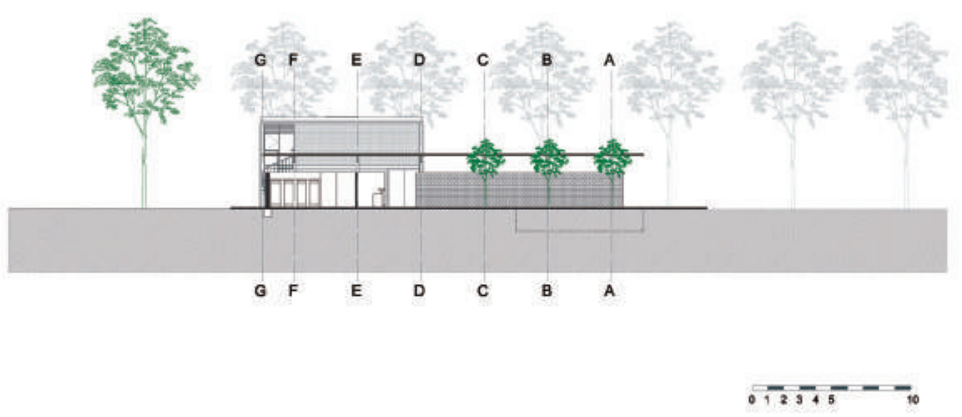

\section{Configuración del edificio}

Distribución de volúmenes respecto al programa funcional: si es manifiesto o contenido. Si el volumen se define por agregación o por vaciado. Identificación de áreas y correspondencia entre ellas, número de plantas y alturas, espacios de circulación y accesos

El programa está fragmentado en dos usos principales: un refugio y un teatro infantil que están distribuidos en cuerpos diferenciados y con particularidades que los hace complementarios: el teatro es cerrado y privado mientras el refugio es radicalmente abierto lo que refuerza la noción de equilibrio basado en equivalencias más no en igualdades, ver Figura 23, algo que también se observa en el manejo de las proporciones con relación a la ocupación del terreno en el primer piso la cual es del orden aproximado de I:I (aquí el equilibrio), pero con diferentes desarrollos en los lados de los volúmenes: el teatro con una base de $18 \mathrm{~m} \times 10 \mathrm{~m}\left(180 \mathrm{~m}^{2}\right)$ y el refugio con una base de $24 \mathrm{~m} \times 7.8 \mathrm{~m}\left(187 \mathrm{~m}^{2}\right)$ (aquí la equivalencia).

Al interior del Teatro el programa se distribuye en tres usos contenidos en un solo volumen: la sala múltiple, un depósito y un cuarto de servicios. Los dos últimos se organizan uno encima del otro acompañando el desarrollo en doble altura del salón múltiple, mientras que en el Refugio el programa se manifiesta en un solo nivel a partir de dos volúmenes agregados bajo una sola cubierta: uno de ellos lleno, el del módulo de fuente de soda y vestieres, y otro vacío de presencia virtual, donde se desarrolla el área de juegos, ver Figura 24. Dicha virtualidad se define con criterios de abstracción que configura ese volumen a través de una cubierta y su estructura junto a un muro divisorio que a lo largo del desarrollo del proyecto va a demostrar ser un elemento que define varias relaciones funcionales formales y técnicas necesarias es un ejemplo de economía como valor visual. El volumen del teatro tiende a ser estático y pesado, contrario al refugio que es dinámico y ligero donde 
Figura 25. Fuente: Mario Narváez Salas.

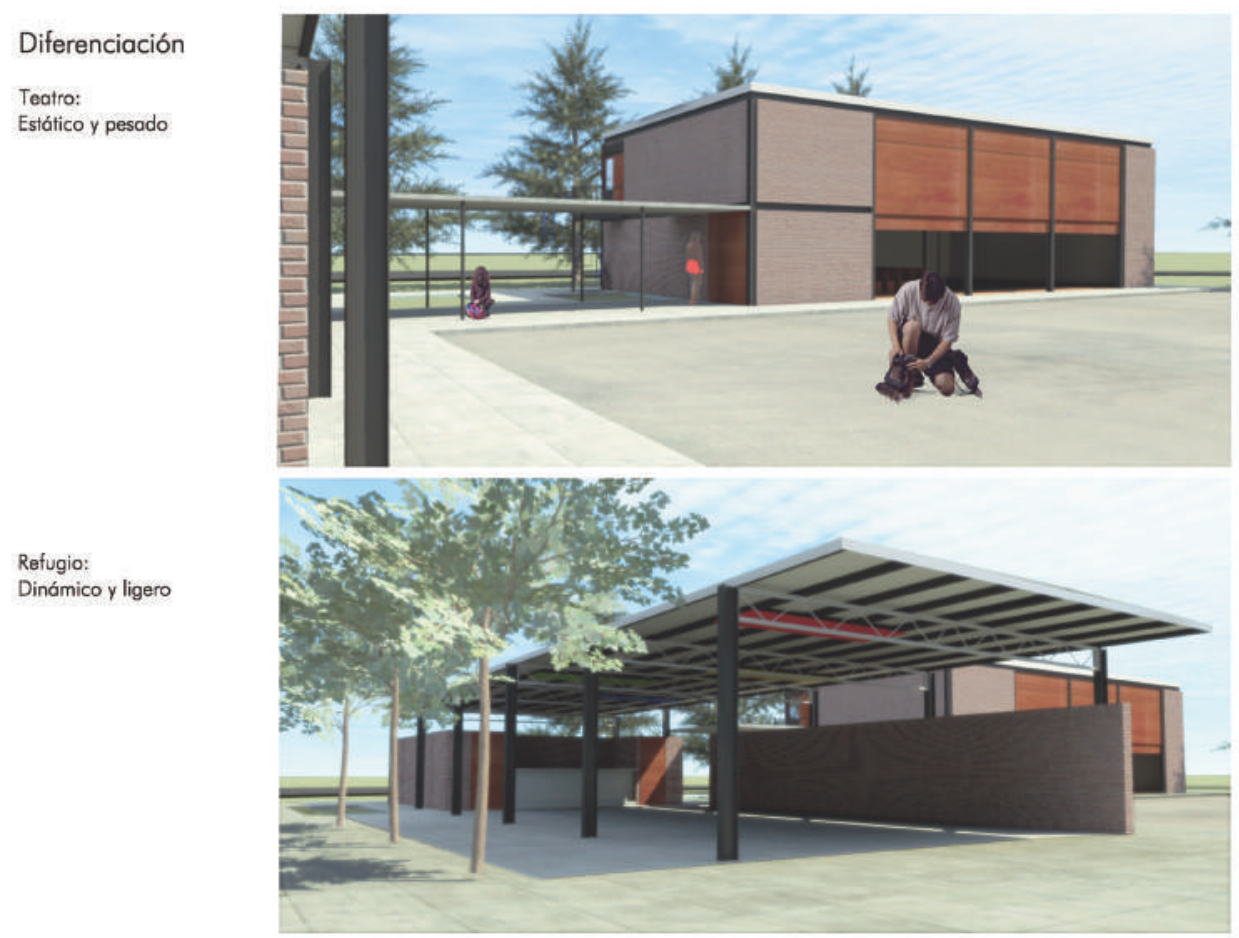

Figura 26. Fuente: Mario Narváez Salas.

Tensiones

Proyecciones refugio

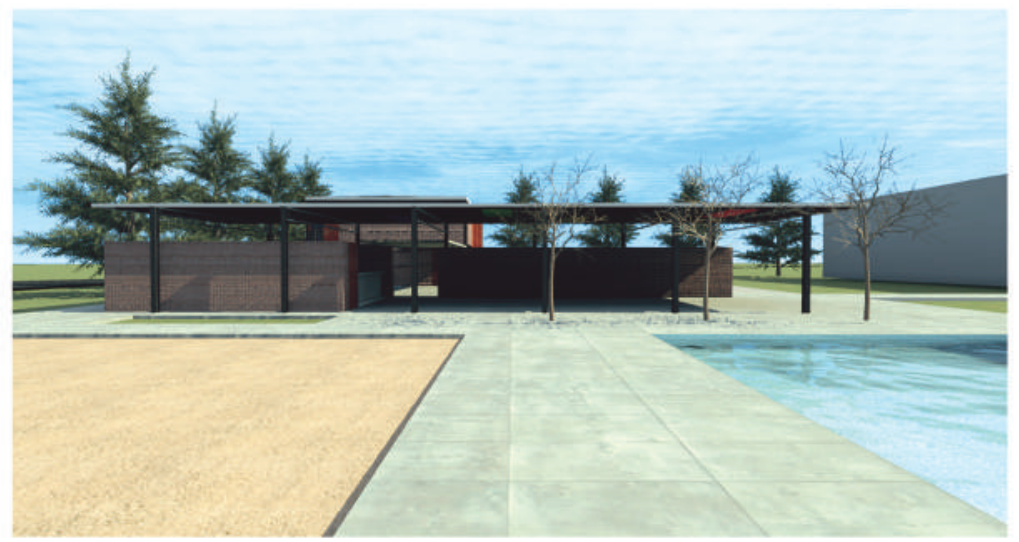




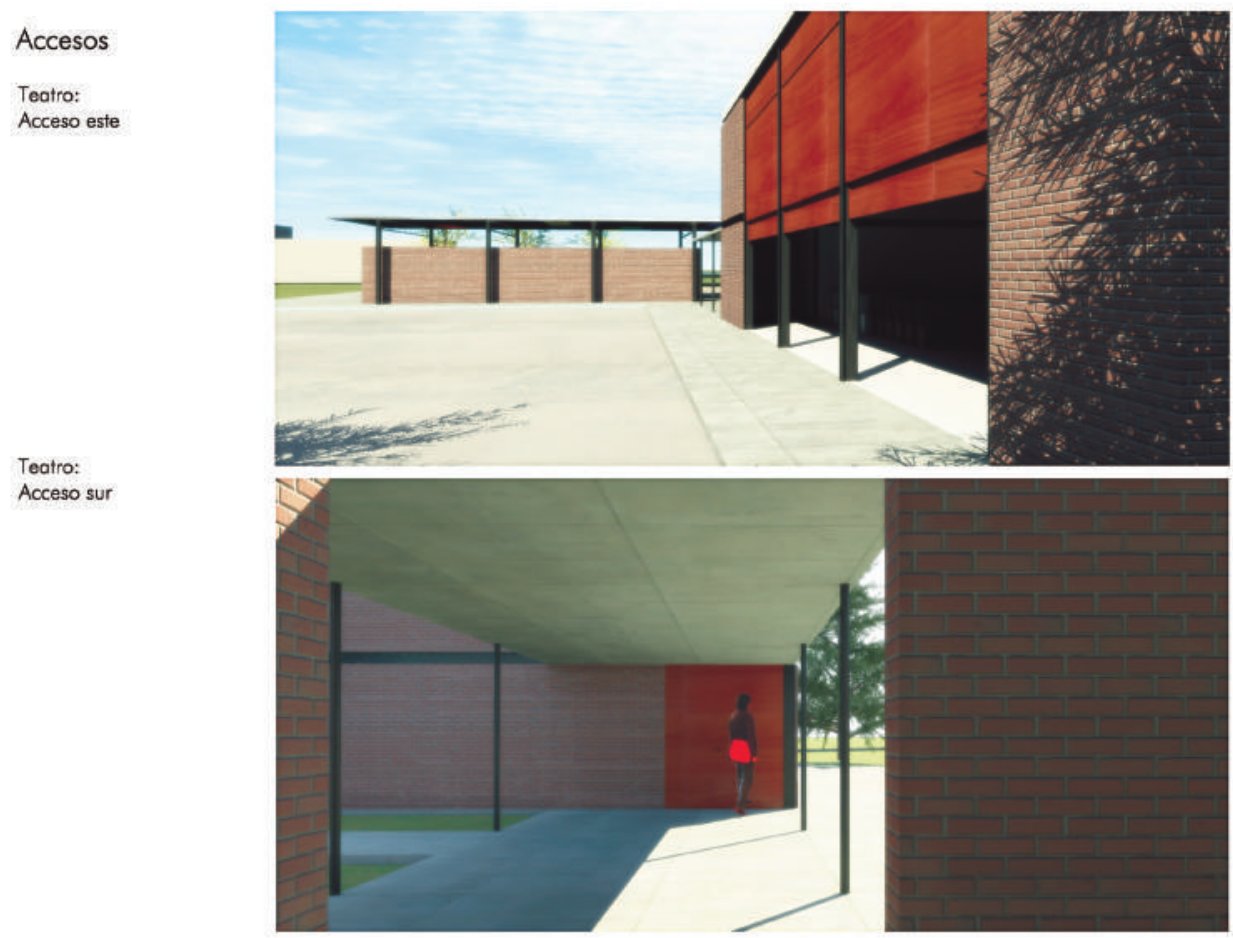

Figura 27.

Fuente: Mario Narváez Salas.

Figura 28.

Fuente: Mario Narváez Salas.

Accesos

Refugio:

Acceso norte

Refugio:

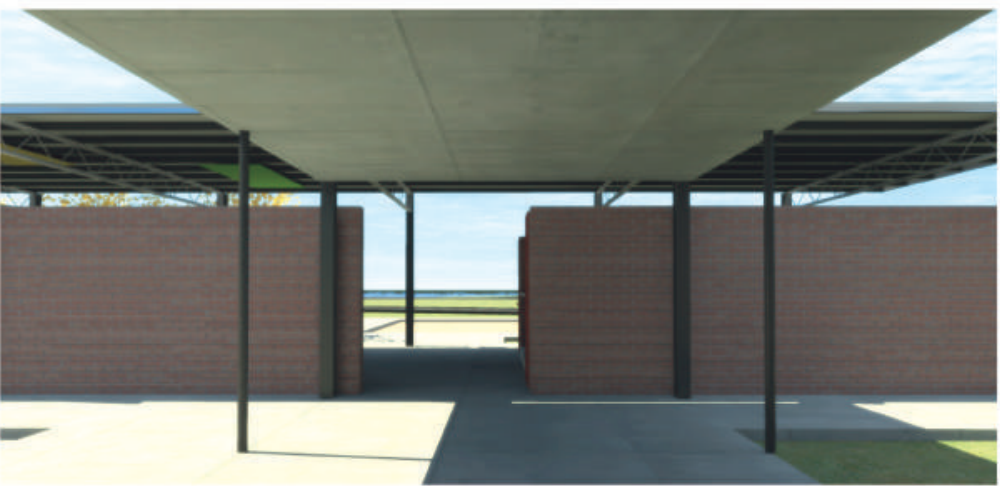

Acceso oeste

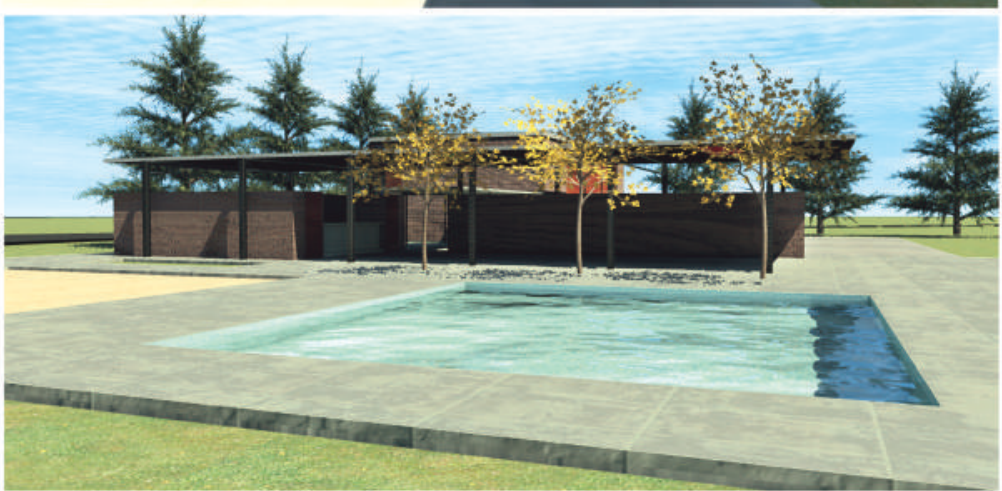


la tensión entre los elementos, diferenciados y relacionados entre sí que constituyen el artefacto, es lo que visualmente lo estructura: por un lado el muro divisorio y el volumen del módulo de vestieres y fuente de soda, y por otro lado la cubierta sostenida por una estructura metálica de perfiles en l y cerchas metálicas. La configuración de estos elementos tensiona a cada uno de ellos con relación a los otros de tal manera que la cubierta resulta levitar, el muro divisorio logra proyectarse en sentido horizontal y el volumen del módulo de vestieres y fuente de soda logra acabar de definir el volumen vacío de la zona cubierta de juegos, son estas relaciones las que definen la volumetría del edificio, ver Figura 25. Otro aspecto que evidencia el equilibrio visual de las tensiones del edificio son las direcciones en que se proyectan los elementos que lo constituyen: la cubierta y el muro lo hacen en sentido horizontal en dirección al edificio existente, mientras que el volumen del módulo de vestieres y fuente de soda lo hace en sentido contrario, hecho que refuerza la noción de equilibrio, ver Figura 26.

En el proyecto se identifican 6 áreas interrelacionadas entre sí: el área de teatro o sala múltiple de $155 \mathrm{~m}^{2}$, el área de depósito y cuarto de servicios del teatro con $35 \mathrm{~m}^{2}$, el área del patio de patinaje y auditorio al aire libre con $448 \mathrm{~m}^{2}$, el área de transición ubicada entre el teatro y el refugio con $100 \mathrm{~m}^{2}$, el área de vestieres y fuente de soda con $48 \mathrm{~m}^{2}$ y por último el área cubierta de juegos con $127 \mathrm{~m}^{2}$.

Respecto a las proporciones, el teatro maneja una relación aproximada de I a 2 en su base mientras el refugio maneja una de I a 3 y el espacio de transición entre los dos edificios una de $1 / 2$ referente al teatro. Este hecho evidencia cómo el rigor y la precisión se aplica en cada una de las escalas del proyecto, desde la implantación y definición de los volúmenes hasta la modulación de los espacios interiores y detalles constructivos: por ejemplo, en el refugio el volumen de los vestieres y fuente de soda maneja una proporción de I a I en la relación de sus lados y de I a 3 con relación a todo el edificio.

El acceso al teatro se hace por el costado este desde el área del patio de patinaje y sobre el costado sur desde el área de transición, definiéndose así una circulación longitudinal sobre el costado este del edificio, ver Figura 27. El acceso al Refugio se hace sobre el costado norte a través de la zona de transición, sobre el costado este a través de la pasarela proyectada para conectar con el edificio principal y sobre el costado sur se accede desde el área de la piscina y pozo de arena frente a los cuales el refugio define un espacio abierto de fácil acceso con circulaciones múltiples y flexibles, ver Figura 28.

\section{Ocupación en planta respecto a la superficie de la parcela y los espacios libres, relación con los accesos y las construcciones y los espacios adyacentes}

La ocupación en planta con relación a la superficie de la parcela es del $25 \%$ quedando $3 / 4$ del lote de superficie libre con una relación de I a 4 y en donde se disponen por un lado el acceso al teatro que coincide con la zona de patinaje lo que genera la posibilidad del auditorio al aire libre, este acceso se articula con la sala múltiple directamente sobre la circulación interior que conecta con la zona de depósitos y cuarto de proyecciones, espacios a los que se accede por circulaciones de servicio independientes. A los depósitos se ingresa por la primera planta sobre el corredor mientras que al cuarto de proyecciones se ingresa por la segunda planta a través de una escalera exterior en forma de caracol. Asimismo, en términos de circulaciones la sala múltiple se vincula con el refugio infantil a través de la mencionada pasarela que se ubica dentro de una zona de transición donde además se localiza la escalera de acceso al cuarto de proyecciones, las circulaciones dentro de esta zona quedan definidas por áreas verdes que acompañan y configuran los recorridos, ver Figura 29. Por otro lado, aparece el acceso al refugio, elemento que es más flexible: a la 


\section{Circulaciones}

Zona de transición, vista escalera de occeso a cuarto de proyecciones
Corte A-A

1. Sala múltiple

2. Auditorio al oire libre

Corte D-D

3. Escalera de acceso cuarto

de proyecciones

4. Pasarelo

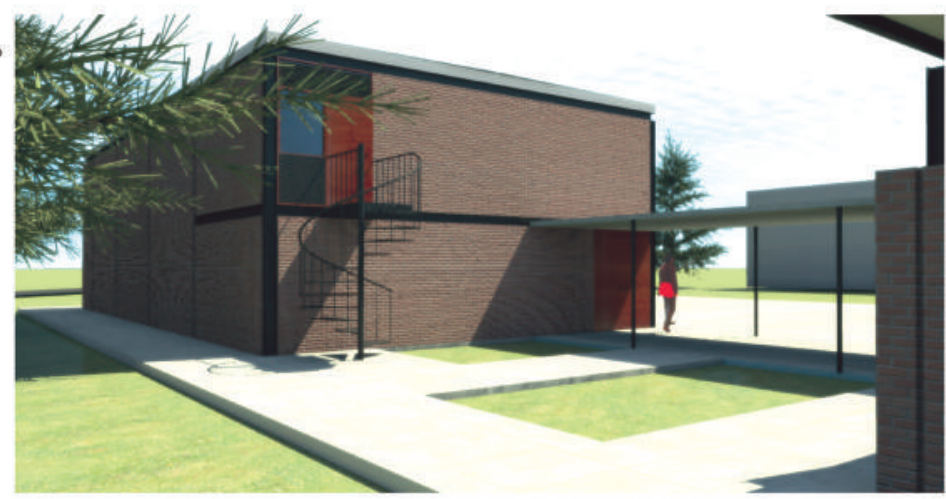

E D

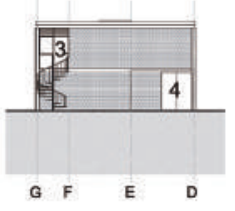

$0, \overline{2} 345-70$

Estructura y cerramiento

Teatro

1. Deposito

2. Sala múltiple

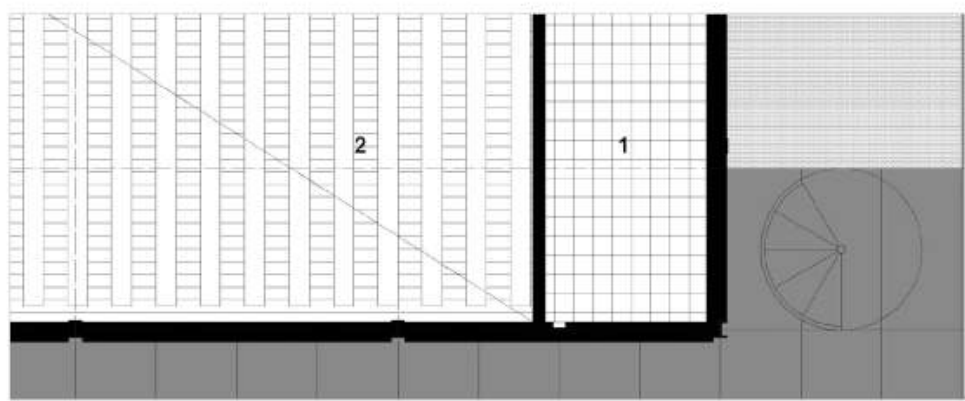

Refugio

3. Vestieres

4. Fuente de soda

5. Zona cubierta de juegos

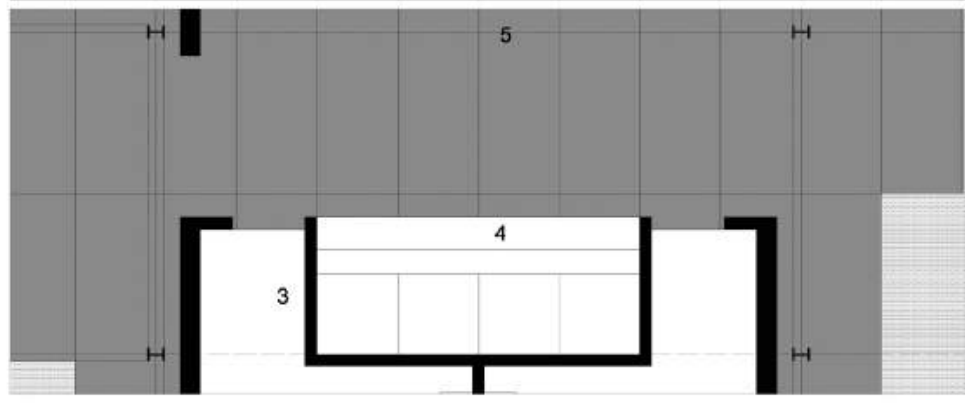

$+$

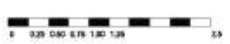


Figura 30. Fuente: Mario Narváez Salas.

\section{Estructura y cerramiento \\ Refugio:}

Visto estructura y cerramiento detolle modulo de vestieres fuente de soda

Detalle corte A-A

1. Columnas en I

2. Cerchas metálicas

3. Correas metólicas

4. Flashing

5. tela asfaltica sobre

Mosonite notural

6. Mamposteria $0.25 \mathrm{~m}$

7. Mamposteria $0.15 \mathrm{~m}$
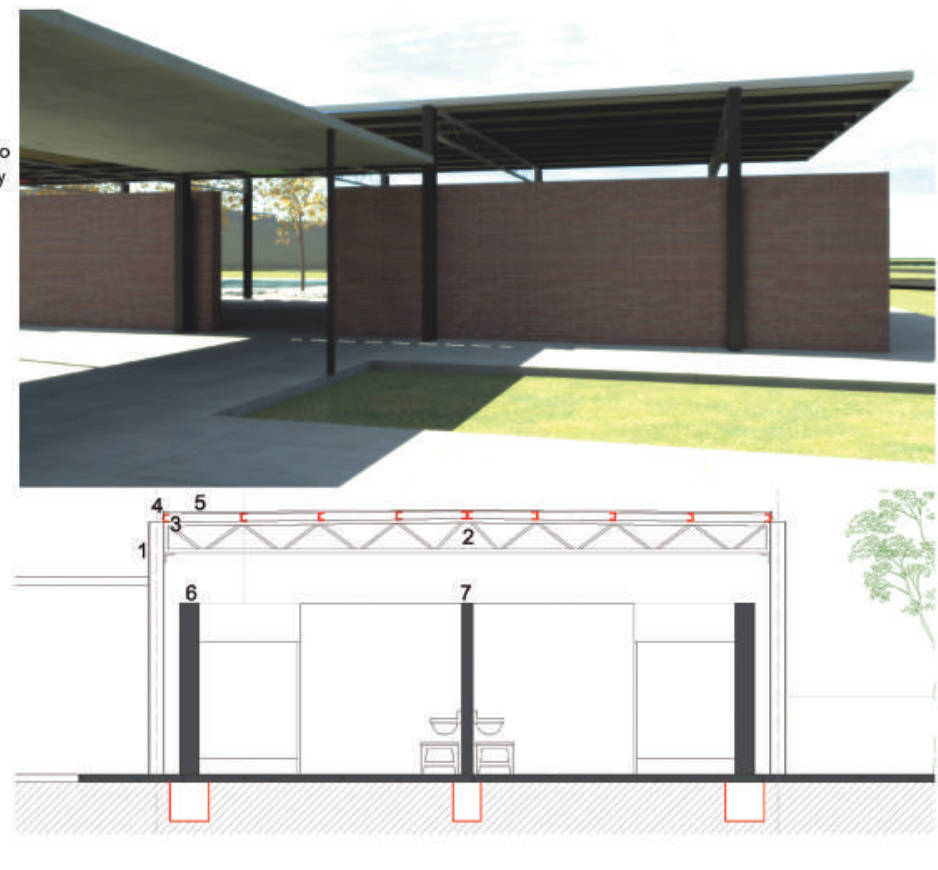

Figura 32. Arriba derecha: Detalle esquina Teatro Club los Lagartos. Abajo derecha. Van der Rohe, Mies. (1945-46). ITT,

Chicago: Alumni Memorial Hall. Fuente: Arriba derecha: Mario Narváez Salas, abajo derecha: Cohen, Jean Louis (1956). Alumn Memorial Hall. Mies Van der Rohe. p.95.

\author{
Estructura y \\ cerramiento \\ Teatro: \\ Vista estructura y cerramiento \\ detalle salido pasarela
}

Alummni Memorial Hall,

Illinois Institute of

Technology, Chicogo,

1945-1946, vista de la

esquina.

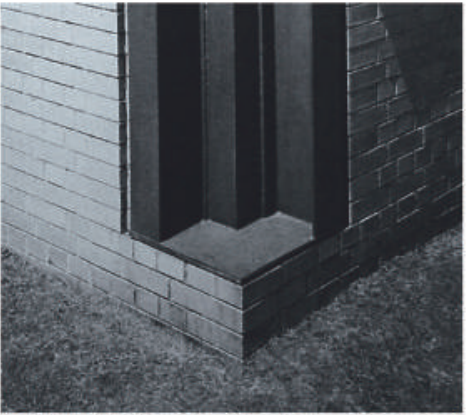


Estructura y cerramiento

Refugio:

Visto estructura y cerramiento detalle muro portante independiente

Refugio:

Vista estructura y cerramiento detalle interior zona de juegos cubierto

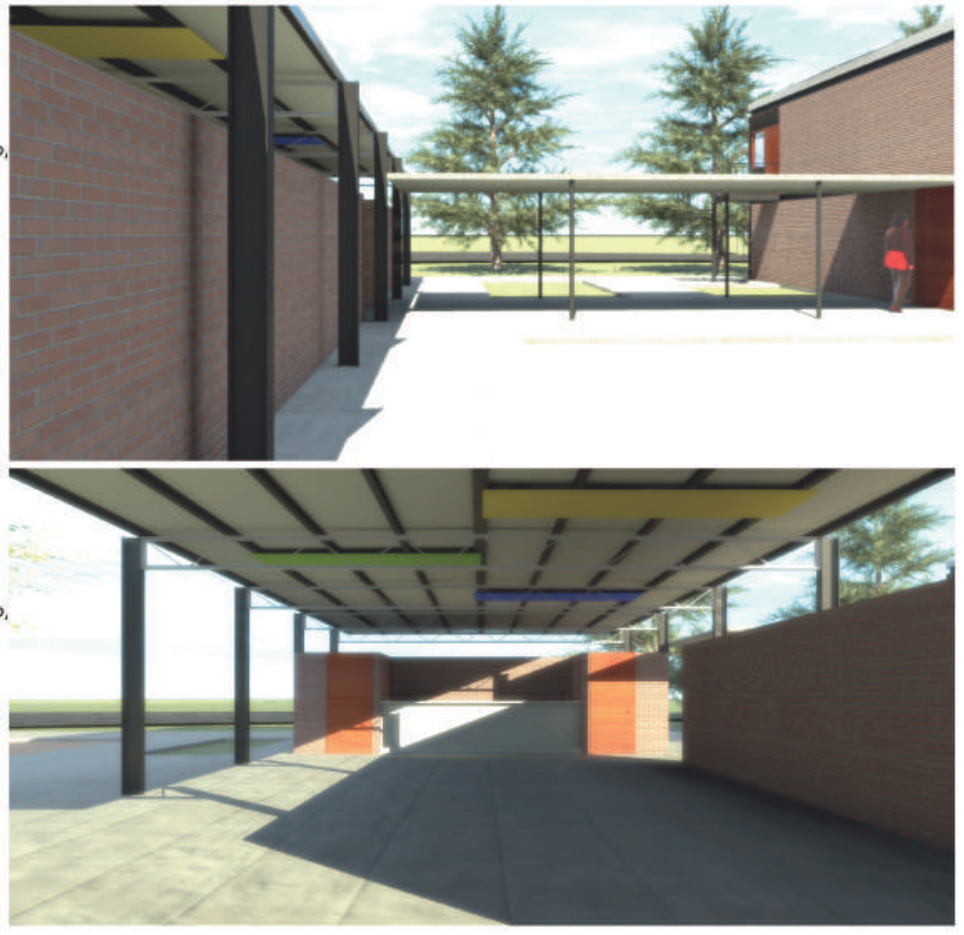

Escalera

Teatro:

Escalera de acceso al cuarto de proyecciones

Masas vegetales

Refugio:

Zona de transición entre la zona de juegos cubierta y la piscina y pozo de areno
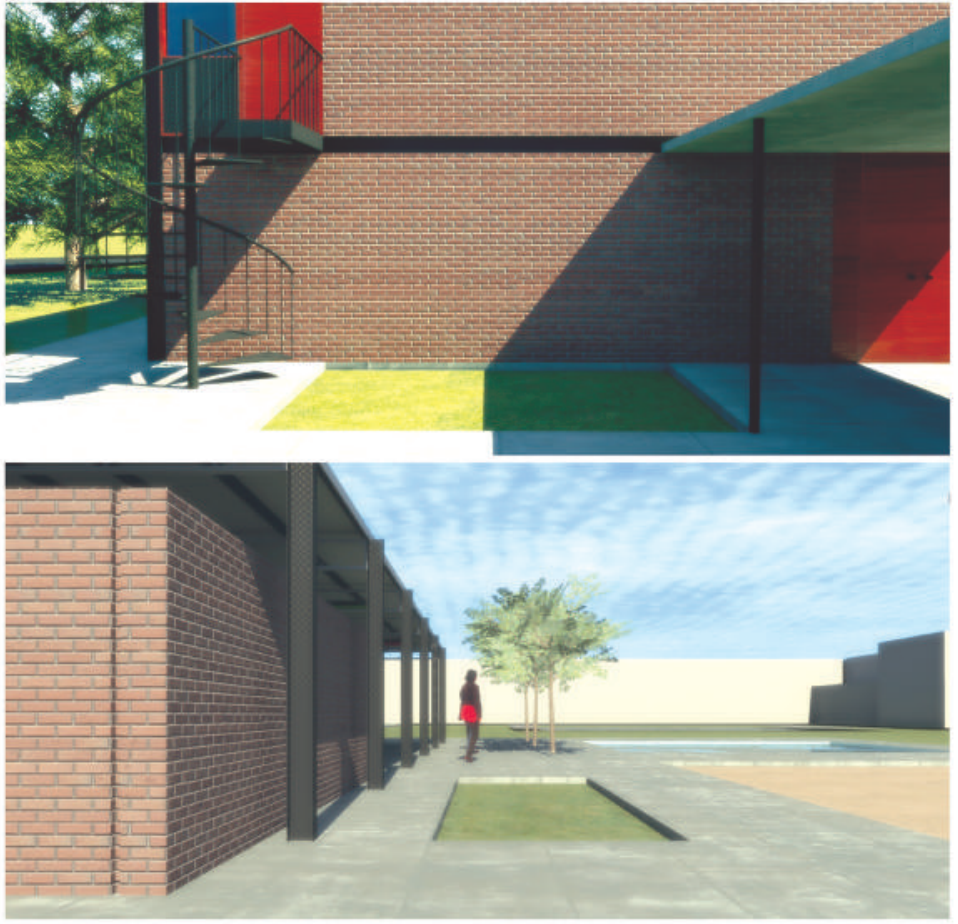

Figura 33.

Fuente: Mario Narváez Salas.

Figura 34.

Fuente: Mario Narváez Salas.

\section{105}


zona cubierta del refugio infantil se accede por el costado este-oeste y sur, cada uno con relaciones particulares: sobre el costado este se encuentra la circulación que conduce al club; sobre el costado oeste se encuentra el área de piscina y pozo de arena, y sobre el costado oeste se encuentra la circulación proveniente del teatro que es la misma que se proyecta sobre el módulo de la fuente de soda y los vestieres.

\section{Determinación de la cota de la planta baja del edificio respecto a la topografía del solar y al espacio público desde el cual se accede}

La cota de la planta baja en todo el proyecto está a +0.06 del nivel del terreno y al nivel 0.00 del nivel del espacio público, espacio desde donde se accede y que facilita de esta manera la posibilidad de existencia de multiplicidad de accesos y circulaciones.

\section{Ordenación de los espacios libres}

Los espacios libres - la pista de patinaje, la piscina, el pozo de arena y los árboles - fueron una situación previa al proyecto. El proyecto se integra en medio de ellos como parte de lo existente y para reforzar de esta manera su autenticidad.

\section{Identificación de los elementos básicos del proyecto}

Sistema portante: si es aparente y tiene propósito formal o queda oculto. En todo caso, es preciso atender a su situación respecto a los cerramientos exteriores y respecto a los elementos de la distribución interior, la distancia entre apoyos, la existencia y la longitud de los voladizos y la modulación.

El sistema constructivo del proyecto surge a partir de una estructura metálica de columnas en I y vigas en forma de cercha unida a un sistema de cerramiento en mampostería en ladrillo; dicha estructura es aparente y fundamental en la configuración de las tensiones formales. En el teatro el cerramiento en mampostería se integra a la estructura metálica mientras que en el refugio se retrae de la estructura para definir cuerpos de estructura independiente lo cual genera una relación donde el muro divisorio del refugio junto con el módulo de fuente de soda y vestieres y la estructura que sostiene la cubierta se encuentran lo suficientemente separados para lograr diferenciarse, pero a la vez se localizan lo suficientemente cerca para tensionarse, es decir, para definir una relación visual que los mantenga unidos y al mismo tiempo lograr definir sus propiedades individuales, ver Figura 30.

La estructura en el teatro maneja unas luces de $10 \mathrm{~m} \times 4 \mathrm{~m}$ que definen 4 módulos completos y medio módulo en voladizo sobre el costado norte. Por otro lado, el refugio maneja luces de $8 \mathrm{~m}$ x $4 \mathrm{~m}$ que definen 5 módulos completos y 2 medios módulos en voladizo sobre los costados este y oeste del proyecto, estos voladizos son los que ayudan a determinar las tensiones de los elementos que lo configuran, ver Figura 31.

Cerramiento exterior: componentes básicos del sistema, materiales, transparencia u opacidad; presencia de módulos fijos o practicables y sus dimensiones; ventilación e iluminación que proporciona al interior; modo de fijación a la estructura; relación con el canto de los forjados, remate superior respecto la cubierta y entrega al suelo. Texturas y colores

El cerramiento exterior en el edificio del teatro está definido por muros de $0.25 \mathrm{~m}$ en mampostería en ladrillo vinculados a la estructura metálica, clara referencia del proyecto del Allumni Memorial Hall (Mies Van der Rohe. 1945). Lo configuran además paneles de 
madera fijos de $2.8 \mathrm{~m} \times 4 \mathrm{~m}$ en la doble altura de la sala múltiple, y paneles móviles de igual dimensión con un sistema de poleas y pesas para el acceso al salón, siendo esta la única fuente de iluminación natural del teatro. Ver Figura 32.

Para el refugio, el cerramiento exterior se define igualmente en mampostería en ladrillo de $0.25 \mathrm{~m}$, pero no está vinculado a la estructura metálica sino que posee una estructura independiente de muros portantes; los únicos paneles con los que cuenta el edifico son las puertas en madera para el acceso a los vestieres. La iluminación natural predomina en la zona de juegos cubierta al ser ésta un espacio totalmente abierto, aunque protegido de los vientos dominantes por medio del muro dispuesto entre el refugio y la zona de patinaje. La estructura surge directamente del suelo a partir de una cimentación de vigas corridas y emplea un sistema de cerchas como remate superior respecto a la cubierta. Los acabados de la estructura son: Ladrillo a la vista, columnas pintadas en negro y cerchas de color blanco, ver Figura 33.

\section{Cubierta: manifiesta o implícita, posibilidad de acceso (si es transitable o no), material de acabado, solución de perímetro, recogidas de agua}

La cubierta es manifiesta más no transitable. El material de acabado es tela asfáltica sobre masonite natural con una solución de perímetro a partir de una pieza continua de metal de $0.15 \mathrm{~m}$ de altura que evita el paso del agua. Las pendientes se manejan al $1 \%$ hecho que refuerza el carácter ortogonal del proyecto. En el teatro se definen bajantes de agua lluvia sobre los muros, mientras que, según la documentación recogida, en el refugio parecieran no emplearse.

\section{Divisiones interiores: relación con la estructura vertical y horizontal y con la fachada. Elementos practicables, materiales, revestimientos calidades y colores, transparencia, modulación de aplacados}

Las divisiones interiores tanto en el refugio como en el teatro son divisiones de $0.12 \mathrm{~m}$ de espesor consecuentes con su función y comportamiento estructural: se vinculan directamente sobre los muros exteriores más no con la estructura vertical ni horizontal. Las puertas como elementos divisorios se desarrollan como paneles opacos en madera natural; el único panel transparente aparece en el acceso al cuarto de proyecciones del teatro.

Escaleras: Situación en planta y en desarrollo, sistema de soporte, recepción superior e inferior, distribución y solución de peldaños - material sujeción, tamaño, relación la estructura-, protecciones laterales

La única escalera presente en el proyecto sirve de acceso al cuarto de proyecciones del teatro y es protagonista de la zona de transición entre el teatro y el refugio. Se ubica como un cuerpo diferenciado e independiente al costado sur del edificio. Posee una estructura metálica con peldaños sujetos con ángulos en cantiléver alrededor de la columna que la soporta. La escalera parte desde el área de vacío de la zona de transición y descarga a un voladizo que surge desde el cuarto de proyecciones del teatro, los peldaños se distribuyen en 12 contrahuellas a lo largo de una altura de $2.64 \mathrm{~m}$ y I I huellas desarrolladas en un radio de $\mathrm{Im}$, dimensiones que definen una altura de huella de $0.22 \mathrm{~m}$ lo que resultaría incómodo para una escalera normal. Sin embargo, al plantearse como una escalera de servicio esta condición debió haberse considerado permisible. Las protecciones laterales son igualmente metálicas con elementos verticales que se descargan en los peldaños, ver Figura 34. 


\section{Pavimentos y falsos techos: material, colores, texturas, despiece, modulación y zócalo}

Los pavimentos al exterior son de concreto lavado y pulido en módulos de $\mathrm{Im} \times 2 \mathrm{~m}$. Al interior del teatro se define esta superficie empleando piso en madera. En los falsos techos aparecen unos elementos en "hardboard" en sentido longitudinal que acompañan la iluminación artificial de los edificios. Tales elementos están dispuestos de manera que se desprenden de la cubierta sujetándose de las correas dispuestas entre las cerchas metálicas y generan tensiones visuales entre ellos al disponerse de manera irregular en módulos policromados de diferentes dimensiones.

\section{lluminación de los espacios interiores: natural y artificial}

Los espacios interiores del teatro se iluminan de forma natural por el acceso esta es la única fuente de iluminación del mismo. En el refugio, sin embargo, las fuentes de iluminación natural son variadas debido a la ausencia general de cerramiento, cuestión que permite ver nuevamente la dualidad presente de manera constante en el proyecto general. Para la iluminación artificial ambos proyectos emplean el mismo sistema de elementos integrados a paneles de "hardboard" del cielo raso.

\section{Mobiliario, si ha sido diseñado por el propio arquitecto, disposición}

Con relación al mobiliario no se encuentra información documentada relevante.

Acondicionamiento de espacios exteriores: límite con el espacio público, pavimentos, distribución de la vegetación -variación a lo largo del año- desmontes y terraplenes, plataformas

Los espacios exteriores se encuentran delimitados por elementos existentes, tales como la piscina y el pozo de arena sobre el costado sur, la pista de patinaje sobre el costado este y pinos de $12 \mathrm{~m}$ de altura en el costado oeste y norte, elementos sobre los cuales el proyecto define su funcionamiento y configuración. Así mismo como el proyecto se relaciona a través de elementos existentes en el espacio exterior también propone unos nuevos, que definen nuevas relaciones a partir de estos: en primer lugar se encuentran los árboles propuestos sobre el costado sur del refugio los cuales dan como resultado un elemento que divide de manera sutil la zona cubierta de juegos de la zona de la piscina, al contrario de la relación que define el muro divisorio entre el patio de patinaje y esta zona. Por otro lado, aparecen una serie de jardines en medio de los pavimentos exteriores los cuales definen circulaciones a la vez que independizan espacios. El juego más interesante de relaciones de equilibrio entre los llenos y vacíos y la vegetación planteada se encuentra sobre la fachada sur del refugio, lugar donde se plantea un jardín de masas bajas sobre el volumen del lleno definido por el módulo de vestieres y fuente de soda, mientras en la zona cubierta que se configura como vacío se plantea una masa de llenos vegetales los cuales tienen la suficiente altura para permitir el paso de las personas entre la piscina y la zona de juegos. 


\section{CONCLUSIONES}

La siguiente validación a manera de conclusión y síntesis, pretende presentar tanto los criterios formales como los valores visuales del Refugio y Teatro infantil como un material de proyecto que pueda brindar la posibilidad de una estructura formal para quien tome el proyecto como referencia, invita a comprometerse en superar el punto de partida para que de esta forma el proyecto pueda resultar distinto al de la materia prima empleada, es decir auténtico.

\section{Valores visuales y criterios formales en el Refugio y Teatro Infantil}

El análisis de las condiciones del emplazamiento y programa fue el espacio propicio para abordar el criterio formal de la concepción, que se da en la medida de cómo el proyecto responde las preguntas que el programa sugiere dentro de un contexto específico, tanto histórico como geográfico, que da como resultado una síntesis de respuestas que dan cuerpo a un objeto arquitectónico auténtico, la forma es un producto de dicha síntesis y no el objetivo inicial.

El Refugio y Teatro Infantil logran validar este criterio formal en la construcción del universo ordenado que define al proyecto a partir de la organización del programa encomendado dentro del contexto descrito en el cual se implanta. En primer lugar aparecen las cuestiones que abordan la fachada orientada hacia el este para definir las aperturas principales del proyecto mientras que la fachada orientada en sentido norte al contrario se cierra para definir un plano totalmente ciego, tanto en el teatro como en el refugio. Particularmente el refugio hace uso de un muro que por un lado protege del viento - tanto al refugio como a la piscina y el pozo de arena - y por otro lado delimita y separa la zona cubierta de los juegos del patio de patinaje y auditorio al aire libre y evita de esta manera interrupciones de los usos previstos en cada una de estas áreas. En segundo lugar, dentro de la relación programa contexto, se puede observar que las respuestas frente al contexto construido cierran la fachada oeste contra la vía de acceso principal y abren la fachada este sobre el edificio existente para disponer los accesos y circulaciones principales. Para reforzar estas intenciones, principalmente la de relación con el edificio existente, el proyecto hace uso nuevamente del muro, el cual proyecta el edificio de refugio en sentido longitudinal sobre la construcción principal de la sede del Club y define la dirección de la pasarela de comunicación prevista y, por otro lado, en sentido perpendicular, hace que el refugio se proyecte sobre la vista predominante del lago. Con relación al contexto histórico se resalta que el edificio en su momento, "especialmente el diseño y construcción de las estructuras metálicas fueron adelantos técnicos considerables" (Martínez, Carlos. 1956. p. 4), así mismo lo afirma Villamizar (2009) donde plantea que:

"La propuesta como tal resultó en extremo innovadora para la época pues en el periodo de los años 1957 a 1960 el ladrillo no era concebido ni se consideraba como un material de acabado que pudiera como tal dejarse a la vista asimilándose dentro del imaginario social y cultural a la condición de pobreza" (p.3.)

y lo confirma Castro (en Villamizar 2009) afirmando que "el ladrillo era siempre un material que había que esconder, cubrir o empañetar"(p.3) 
En la configuración del edificio se alcanzan a validar valores como: la economía, a través del muro y sus diversas relaciones tanto funcionales, formales y técnicas; el equilibrio, a través de la complementación de relaciones entre privado y público, lleno y vacío, estático y dinámico, al mismo tiempo que pesado y ligero presentes entre el volumen del teatro y el del refugio. La tensión en equilibrio es evidente en las relaciones entre los elementos que configuran el refugio de tal manera que la cubierta resulta levitar, el muro divisorio logra proyectarse en sentido horizontal en dirección del edificio principal y el volumen del módulo de vestieres y fuente de soda logra terminar de definir el volumen vacío de la zona cubierta de juegos, estas relaciones son las que definen la volumetría del edificio. Otro aspecto que evidencia el equilibrio visual de sus elementos son las direcciones en que se proyectan los elementos que lo constituyen: tanto la cubierta como el muro lo hacen en sentido horizontal en dirección al edificio existente, mientras el volumen del módulo de vestieres y fuente de soda lo hace complementariamente en sentido contrario. El rigor y la precisión se observan en el manejo de las proporciones y el desarrollo en todas las escalas del proyecto; la abstracción como valor visual se observa en la configuración de la volumetría: en el refugio se podría denominar virtual ya que su presencia surge a partir de la ausencia, para definir un vacío donde el refugio desarrolla el área de juegos, dicha virtualidad se define a través de la relación entre la cubierta y su estructura, el muro divisorio junto al volumen de la fuente de soda y vestieres, al contrario de lo que pasa en el teatro donde el vacío se define contenido por el cerramiento que configura la masa y llenos del edificio y refuerza la idea de equilibrio a partir de equivalencias mas no en igualdades.

Los elementos básicos que definen el proyecto en detalle refuerzan los distintos valores visuales en cada escala correspondiente. Por ejemplo, en todo el proyecto la modulación estructura la configuración de los espacios y ayuda a definir las proporciones, hecho que aclara la noción de precisión, como la medida justa, ni más elementos que propicien el despilfarro ni la escasez premeditada de elementos como recurso estilístico o de maquillaje de lo mínimo, y facilita además el desarrollo del rigor en la propuesta, como la implementación consecuente de los criterios formales en todas las escalas del objeto. Por otro lado, los elementos del sistema constructivo condicionan las posibilidades formales y a partir de su comprensión el proyecto logra desarrollar una propuesta consistente y unitaria a pesar de la dualidad de características existente en los edificios que configuran el proyecto, tanto el refugio como el teatro infantil. Asimismo los elementos que definen el refugio ayudan a validar la noción de tensión en equilibrio de manera que están lo suficientemente separados para lograr diferenciarse, pero lo suficientemente cerca para definir una relación visual que los mantenga unidos a la vez que logran definir sus propiedades formales individuales.

Con la anterior validación se puede concluir que el proyecto de Refugio y Teatro Infantil para el Club los Lagartos se puede reconocer como un edificio que ofrece criterios de orden capaces de ser utilizados en otros proyectos en iguales o distintas condiciones. 


\section{REFERENCIAS}

Colombia Architettura Moderna. (2009). http://www.muva.it/

FONTANA María Pía. (2004). Colombia: Arquitectura Moderna. Barcelona: ETSAB.

GASTÓN Cristina \& Rovira, Teresa. El Proyecto moderno. Pautas de investigación. (2007) Barcelona: Ediciones UPC.

MARTíNEZ Carlos. (1956). Refugio y teatro infantil en el club los Lagartos. Proa, 97,3-5

MARTÍNEZ Carlos. (1956). Las mejores edificaciones Bogotanas en los últimos diez años. Proa, 100, 5

PIÑÓN Helio. (1998). Curso Básico de Proyectos. Barcelona: Ediciones UPC.

PIÑÓN Helio. (2005). Materiales de proyecto. Barcelona: Ediciones Helio Piñón.

PIÑÓN Helio. (2006). Teoría del proyecto. Barcelona: Ediciones UPC.

Programa de Doctorado en Proyectos Arquitectónicos. Recuperado el I 5 de Marzo de 2009 de http://doctorat.upc.edu/estudis/programa.php?idprog $=280$

SALDARRIAGA ROA Alberto. (1989). La arquitectura bogotana y el Club los Lagartos. Proa, 384

VILLAMIZAR HERNÁNDEZ, Jorge Alberto. (2009). Entrevista con Dicken Castro, Arquitecto. Bogotá. Documento inédito. 